Article

\title{
A Numerical Investigation into the PAT Hydrodynamic Response to Impeller Rotational Speed Variation
}

\author{
Maxime Binama ${ }^{1} \mathbb{D}$, Kan Kan ${ }^{2, *}$, Hui-Xiang Chen ${ }^{3} \mathbb{D}$, Yuan Zheng ${ }^{1,2}$, Da-Qing Zhou ${ }^{1,2} \mathbb{D}$, Wen-Tao Su ${ }^{4}$, \\ Xin-Feng $\mathrm{Ge}^{2}$ and Janvier Ndayizigiye ${ }^{1}$
}

1 College of Water Conservancy and Hydropower Engineering, Hohai University, Nanjing 210098, China; binamamaxime@hhu.edu.cn (M.B.); zhengyuan@hhu.edu.cn (Y.Z.); zhoudaqing@hhu.edu.cn (D.-Q.Z.); janvier.ndayizigiye@outlook.com (J.N.)

2 College of Energy and Electrical Engineering, Hohai University, Nanjing 210098, China; gexinfeng@hhu.edu.cn

3 College of Agricultural Science and Engineering, Hohai University, Nanjing 210098, China; chenhuixiang@hhu.edu.cn

4 College of Petroleum Engineering, Liaoning Shihua University, Fushun 113001, China; wentaosu@Inpu.edu.cn

* Correspondence: kankan@hhu.edu.cn

Citation: Binama, M.; Kan, K.; Chen, H.-X.; Zheng, Y.; Zhou, D.-Q.; Su, W.-T.; Ge, X.-F.; Ndayizigiye, J. A Numerical Investigation into the PAT Hydrodynamic Response to Impeller Rotational Speed Variation. Sustainability 2021, 13, 7998. https:// doi.org/10.3390/su13147998

Academic Editor: Alessandro Franco

Received: 21 June 2021

Accepted: 12 July 2021

Published: 17 July 2021

Publisher's Note: MDPI stays neutral with regard to jurisdictional claims in published maps and institutional affiliations.

Copyright: (c) 2021 by the authors. Licensee MDPI, Basel, Switzerland. This article is an open access article distributed under the terms and conditions of the Creative Commons Attribution (CC BY) license (https:// creativecommons.org/licenses/by/ $4.0 /)$.

\begin{abstract}
The utilization of pump as turbines (PATs) within water distribution systems for energy regulation and hydroelectricity generation purposes has increasingly attracted the energy field players' attention. However, its power production efficiency still faces difficulties due to PAT's lack of flow control ability in such dynamic systems. This has eventually led to the introduction of the so-called "variable operating strategy" or VOS, where the impeller rotational speed may be controlled to satisfy the system-required flow conditions. Taking from these grounds, this study numerically investigates PAT eventual flow structures formation mechanism, especially when subjected to varying impeller rotational speed. CFD-backed numerical simulations were conducted on PAT flow under four operating conditions (1.00 $\mathrm{Q}_{\mathrm{BEP}}, 0.82 \mathrm{Q}_{\mathrm{BEP}}, 0.74 \mathrm{Q}_{\mathrm{BEP}}$, and $\left.0.55 \mathrm{Q}_{\mathrm{BEP}}\right)$, considering five impeller rotational speeds (110 rpm, $130 \mathrm{rpm}, 150 \mathrm{rpm}, 170 \mathrm{rpm}$, and $190 \mathrm{rpm}$ ). Study results have shown that both PAT's flow and pressure fields deteriorate with the machine influx decrease, where the impeller rotational speed increase is found to alleviate PAT pressure pulsation levels under high-flow operating conditions, while it worsens them under part-load conditions. This study's results add value to a thorough understanding of PAT flow dynamics, which, in a long run, contributes to the solution of the so-far existent technical issues.
\end{abstract}

Keywords: flow dynamics; numerical simulation; pressure pulsation; pump as turbine; rotational speed

\section{Introduction}

The use of fossil fuels as main energy sources goes with a number of shortfalls, environmental disruption, and possible reserves for depletion, among others [1]. Fossil fuels are linked to the widely condemned greenhouse gas emission, i.e., gases which are believed to be at the source of climate change and other detrimental effects [2]. Of course, the non-renewable nature of fossil fuels itself poses a threat of resources exhaustion in the near or far future [3]. With the international will on reducing the $\mathrm{CO}_{2}$ emissions, renewable energy sources (REN) have been advocated, and countries have taken action to not only involve RENs in their power systems, but to continue increasing RENs annual productions [4,5]. Among the so far available RENs, hydropower is one of the most mature REN technologies that dominates the market with a multitude of hydrosites already expanding the whole world over [6,7]. Hydropower technology is linked to different advantages when compared to other REN technologies, including their huge energy storage 
ability and operational flexibility, among others. Depending on different aspects, the targeted production and site-available potential among others, hydropower technology exploits natural waters from all sorts, such as seas, lakes, rivers, and estuaries. This also somehow leads to the classification of hydrosites as large- or small-scale hydrosites [8]. While large hydropower plants are generally known to feed large-size power grids such as the national or even international grids, small hydropower is mostly used under off-grid operational mode, contributing to the electrification of rural areas which not only provides electric lighting for households but also contributes to other economic activities such as the agricultural irrigation [9-11].

With the continued research on hydropower development, water supply and irrigation systems have been found to be another alternative for hydropower production on small scales [12]. In these systems, water flows continuously, thus presenting a stable hydropower potential. Besides, system excess energy in terms of pressure is usually wasted through pressure-reducing valves (PRVs) to avoid water leakages [13]. The installation of hydraulic turbines in these networks not only replaces the formerly utilized valves in regulating the system's energy levels but also uses that same energy to produce usable electric power [14-17].

Now, as also mentioned by different investigators, for small-scale hydropower (SHP) projects, the initial installation budget is the most expensive as the electromechanical equipment takes up a considerably high percentage of the total investments, in the range from $35 \%$ to $40 \%$ or even beyond [18,19]. In line with this, the utilization of normal hydraulic pumps in reverse mode, as an economic alternative to SHP installation budget, has recently attracted the attention of many REN field players [20,21]. In addition to its cost-effectiveness, pump as turbines (PATs) present different advantages over comparable mini-scale hydroturbines, including the easy availability of the machine itself and spare parts, structural simplicity, easy maneuverability, short delivery time, and a long life span $[22,23]$.

Nevertheless, PAT technology has also shown different shortfalls. Among others, the so far controversial conversion of pump-mode performance characteristics to turbine mode is the most researched, where the so far available analytical conversion methods present errors in the range of $\pm 20 \%$ [24]. Scientific research on this matter still goes on as of today. For more about PAT turbine mode performance predictions, review articles by Jain et al. [24], Elbatran et al. [25], Adu et al. [26], and Ntiri et al. [27] are recommended.

Another problem about PAT technology resides in its structural design that does not necessarily meet the energy production requirements. This aspect itself plays a big role in the above-mentioned difficulty in PAT's turbine mode performance prediction. To be more specific, the pump impeller blades are curved in the opposite direction of its rotation (backward). This blade design becomes forward-curved when the flow direction changes in turbine mode, thus serving the source to large flow separations and associated hydraulic losses as a result of flow impingement on the blade's pressure side in the vicinities of its leading edge. In addition, hydraulic pumps are not necessarily provided with flow control mechanism. Therefore, the machine is unable to regulate the flow rate or the water flow incidence angle to satisfy the demanded operating conditions. This also explains its inability to handle off-design operating conditions. Therefore, PATs have been found to optimally function in a tiny range of flows around the best efficiency point (BEP), while they operate poorly under off-design conditions [28]. This constitutes one of the biggest shortfalls of PAT technology and has attracted the attention of many researchers, mainly targeting the understanding of PAT flow dynamics and subsequently attempting to widen its optimum operating range. Among the recently published findings, one would cite a study conducted by Štefan et al. [29] on PAT internal flow field under both pump and turbine modes. In total agreement with the literature, the turbine mode was found to attain its BEP under a higher head and flow rate, as compared to the pumping mode ( $41 \%$ and $27 \%$, respectively), while the efficiency was slightly lower $\left(\eta_{T}=0.96 \eta_{P}\right)$. Moreover, a steep drop on the PAT efficiency curve has been noticed for deep part-load operating conditions, supposedly owing to the intensification of swirling flows within the PAT's 
outlet pipe. Based on the fact that, for fluid machinery, adverse flow phenomena mostly occurring under unstable conditions led to increased energy loss rates, Lin et al. [30] has used the entropy dissipation theory to study PAT operating characteristics under off-design operating conditions. As expected, unsteady flow phenomena such as the backflows, shock flows, and vortical flows, have inflicted higher entropy and energy dissipation, where flow zones with the highest energy losses have been pointed out as the vicinities of the blade leading edge, the cavity zone (impeller's back and front chambers), and volute throat. In the same respect, Guan et al. [31] and Morabito et al. [32] found that the position and geometry of the volute throat may influence the machine energy loss characteristics and its efficiency.

More studies have also been conducted to try and decrease PAT hydraulic losses through different technics, geometry modification, and optimization, among others. To say the least, Ghorani et al. [33,34], after finding that irreversible hydraulic losses associated with flow shock at the blade leading edge and other secondary flow phenomena such as backflow and vortices take place within PAT flow zones, have opted to optimizing the PAT impeller geometry, leading to substantial reduction in the above-stated unsteady flow phenomena and a corresponding increase in the machine hydraulic efficiency for different operating conditions ( $3.8 \%$ and $5.72 \%$ for $\mathrm{Q}_{\mathrm{BEP}}$ and $1.3 \mathrm{Q}_{\mathrm{BEP}}$ flow conditions, respectively). In the same respect, Wang et al. [35] mentioned that one of most cost-effective ways to improve PAT's turbine mode performance would be by redesigning its blade geometry without touching other components. Therefore, they designed a special impeller with forward-swept blades and compared its performance with the original back-swept bladed one. The special impeller, owing to the associated considerable reduction in impeller hydraulic and shock losses, exhibited a flatter efficiency-flow rate curve ( $\eta-Q$ curve), thus promising a larger range of optimum operating conditions around the BEP (1.5\% efficiency variation for flow conditions within the range from $0.9 \mathrm{Q}_{\mathrm{BEP}}$ to $\left.1.2 \mathrm{Q}_{\mathrm{BEP}}\right)$. Moreover, a $7.9 \%$ increase in the maximum attainable efficiency was achieved, thus confirming the special impeller's superiority over the original one. In the same respect, Sengpanich et al. [36] proposed "an impulse pump-as-turbine" using an injector as a flow control mechanism. This technique also assured a continuously high efficiency for a wide range of flows.

Coming back to the application of PAT technology in water distribution networks (WDNs), different studies have so far been carried out [25,37-40], which concern the abovediscussed PAT technology-associated problems. Consequently, the current technology readiness level (TRL) for PAT technology is estimated at TRL $-4[41,42]$. The utilization of PATs in WDNs must consider the variability of pressure and flow rate as imposed by the system, due to the instantaneity in water demands [43-45]. In this respect, Carraveta et al. [46-48] have developed a so-called "variable operating strategy" or VOS, with the aim of efficiently using PAT technology to regulate the WDN energy. This strategy consists of two distinct regulation methods, namely hydraulic regulation (HR) and electric regulation (ER), though they can also be combined to give new regulation features. The HR method consists of the usage of PAT in a series-parallel circuit with PRVs where the system energy regulation is mainly achieved by just acting on the utilized PRVs. The valve in series with PAT is used to dissipate the surplus energy leading to a lower system flow as compared to PAT's BEP flow $\left(Q_{S}<Q_{T}\right)$, while the valve in parallel with PAT bypasses a quantity of flow thus shifting the system operating point to higher flows $\left(Q_{S}>Q_{T}\right)$. As for the ER method, an electric inverter is used to regulate the impeller rotational speed (IRS) where, for instance, one would increase the IRS to shift the system operating point to lower flows, or decrease it to obtain the system operating point to higher flow conditions. In this method, however, owing to a comparatively narrow range of system operating conditions between the runaway $(T=0 \mathrm{Nm})$ and resistance $(R R S=0 \mathrm{rpm})$ characteristic curves, high IRS values may lead to a system operating point where the runner rotational speed is close to the runaway value, possibly causing PAT's poor performance. To avoid this situation, a series-PRV can be used to shift the IRS to lower values, while respecting the system-required operating point. VOS functionality discussions and applications have 
been presented through a number of studies by Fecarrota et al. [49] and Stefanizzi et al. [41], among others.

Specifically, the utilization of variable-speed PATs in WDNs as a means to control the flow while keeping a good system operational efficiency has so far been researched by different authors, including Delgado et al. [50], Lima et al. [51], and Tahani et al. [52], among others. In most of these studies, the main focus has been the optimization of selection, position, and utilization of variable-speed PATs, targeting the improved WDN energy regulation and efficient energy recovery. On the other hand, a few more studies have been conducted on the effect of PAT speed variation, but considering its application to normal hydropower production within small-scale hydroelectric plants, where the machine external performance characteristics have been the focus $[53,54]$. What is also worth mentioning is a study on the effect of PAT rotational speed variation on tip leakage vortex (TLV) dynamics under pump mode, as conducted by Han et al. [55], where the TLV was found to worsen with an increase in PAT impeller rotational speed. To the authors best knowledge; literature is so far quite limited on the impact of impeller rotational speed variation on PAT flow dynamics under turbine operating mode.

Therefore, by targeting a thorough understanding of PAT flow dynamics under these circumstances, especially considering PAT's off-design operating conditions, the present article presents a numerical investigation on the formation mechanism of PAT flow structures, and the effect of impeller rotational speed variation on the same. CFD-backed numerical simulations have been conducted on PAT's 3D turbulent flow under optimal condition and three part-load conditions (1.00 $\mathrm{Q}_{\mathrm{BEP}}, 0.82 \mathrm{Q}_{\mathrm{BEP}}, 0.74 \mathrm{Q}_{\mathrm{BEP}}$, and $\left.0.55 \mathrm{Q}_{\mathrm{BEP}}\right)$, where five impeller rotating speeds, namely $110 \mathrm{rpm}, 130 \mathrm{rpm}, 150 \mathrm{rpm}, 170 \mathrm{rpm}$, and $190 \mathrm{rpm}$, were considered.

The investigated model is a mixed flow PAT with a three-bladed impeller and a flow control system of seven guide vanes. This article is composed of three main sections. Section 1 provides an extensive background on PAT technology and the associated technoscientific issues, as well as the so far attained level of knowledge. Section 2 describes both the investigated case and utilized methods. Section 3 provides a thorough discussion on the present study's findings, which finally led to a number of concluding remarks.

\section{Materials and Methods}

In order to achieve this study's objective, a roadmap was designated and followed, as shown by the flowchart in Figure 1. The PAT prototype was first experimentally tested under various operating conditions to finally obtain the pump as turbine's external performance characteristics in terms of Head $(\mathrm{H})$ and Efficiency $(\eta)$.

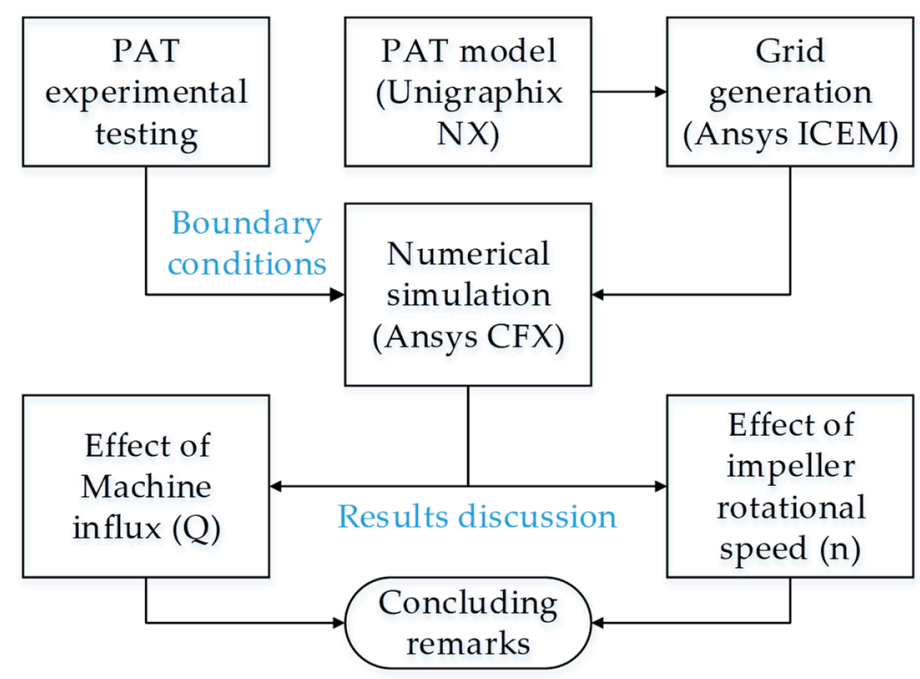

Figure 1. Study roadmap. 
Then, a PAT geometrical model was built, from which a predominantly hexahedral computational grid was later generated. The resultant grid was taken to ANSYS CFX-Solver (developed by Ansys, Inc., an American company based in Canonsburg, Pennsylvania) for PAT flow simulation under various operating conditions, as also mentioned in the last sections of the article.

During simulation, the experimental test-extracted data were used as system boundary conditions, and the utilized numerical scheme validation was later performed by comparing experimental and numerical simulation results. Finally, farther study results in terms of machine flow and pressure field characteristics with gradually changing machine influx (Q) and impeller rational speed (n) were extracted, and deeply analyzed, leading to a number of concluding remarks.

\subsection{PAT Geometry}

The research object of this study is a mixed-flow pump as turbine (PAT) composed of four main components, namely the inlet pipe (IP), the impeller, the guide vanes (GV) zone, and the outlet pipe $(\mathrm{OP})$. The impeller had 3 blades $\left(Z_{R}=3\right)$ while the guide vanes zone was composed of 7 guide vanes $\left(Z_{G}=7\right)$. Both the inlet and outlet pipes were split type tubes. The model's specific speed $\left(\mathrm{N}_{\mathrm{Q}}\right)$ was $163.9 \mathrm{~min}^{-1}$. The impeller diameter was $320 \mathrm{~mm}$, while its outlet diameter was $300 \mathrm{~mm}$. The guide vanes inlet diameter was $350 \mathrm{~mm}$, and there was no existent blade tip clearance. A corresponding computational domain was built and simulated using Unigraphix NX8.0 (owned by Siemens PLM, an American company based in Plano, TX, USA) and Ansys CFX softwares, respectively. Figure 2 shows the utilized PAT computational domain and its components.

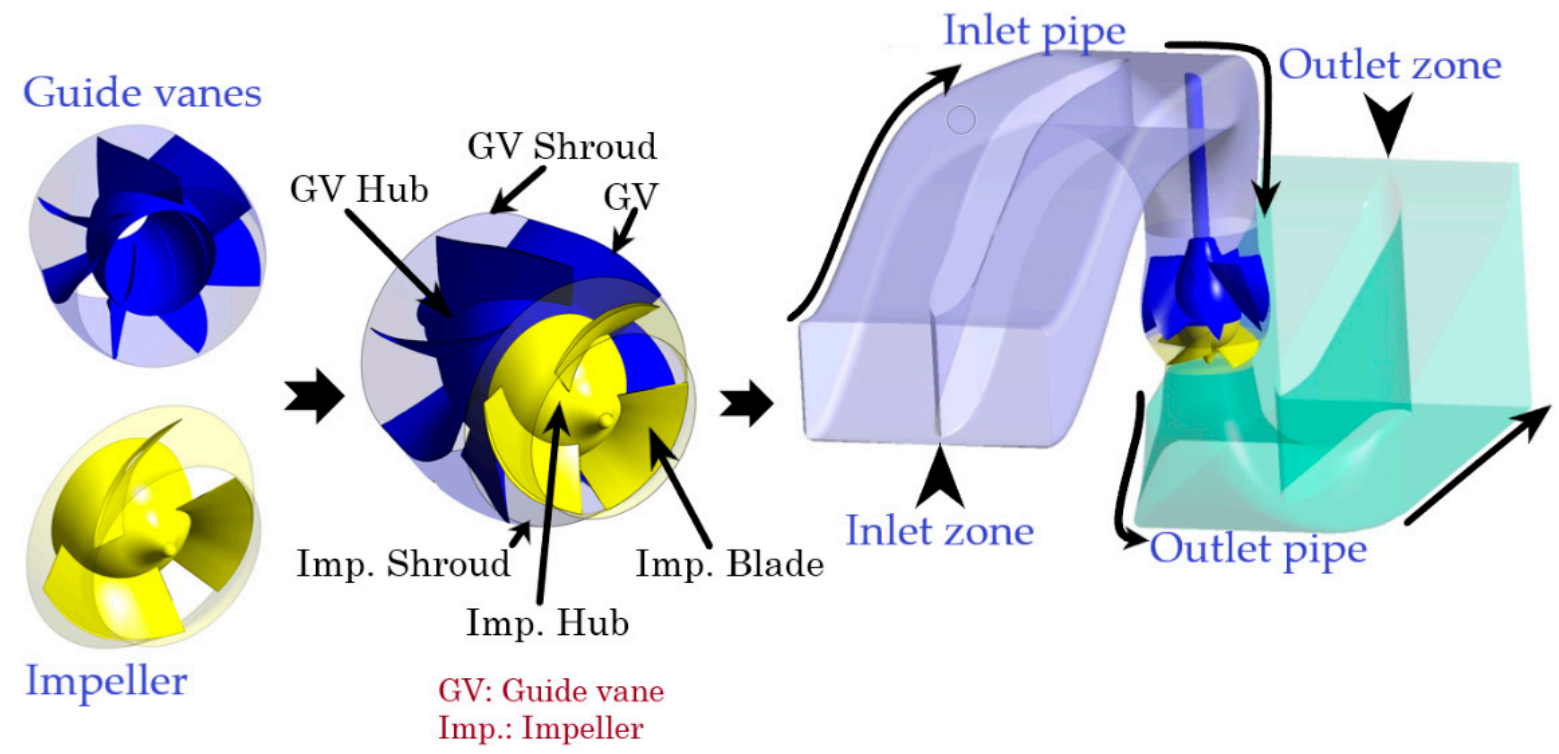

Figure 2. PAT computational domain and components.

\subsection{Grid Generation}

Grid generation constitutes one of very important phases of the numerical simulation process. The generated grid's quality is a very crucial parameter, as it plays a fundamental role on different aspects, numerical solution convergence, and accuracy within numerical simulation results, among others. Therefore, great attention is always paid to this phase. Depending on different factors such as the geometry complexity or the nature of simulated system's operations, grid characteristics can be varied at different flow zones.

For the case of an axial-flow PAT, which is this study's case, flow separations are likely to take place in rotating parts and the adjacent flow zones. Therefore, for the sake of accurately capturing the flow dynamics at those zones, a finer grid was created around the impeller blades and guide vanes, leading to a global $y+$ value less than 50 . Ansys 
ICEM software was used to generate this grid, where the hexahedral mesh type was utilized for all of the components of the computational domain. In order to avoid the possibility of numerical simulation results being influenced by the utilized grid number, a grid independence test was carried out where six different grid numbers ranging from 4 to 8 million were tested. Having been simulated under the same boundary conditions, different grid numbers have led to different values of PAT's hydraulic head. Table 1 displays the head variation with the increasing grid number from 4 to 8 million elements. It can be seen that the head increased with the grid number until 7.2 million, after which the head value approximately stabilized. Therefore, in line with the available computational resources, a grid number of 7.2 million was chosen for further transient simulations. Details of the selected grid are presented in Table 2.

Table 1. Hydraulic head variation with different grid numbers.

\begin{tabular}{|c|c|c|c|c|c|c|}
\hline $\begin{array}{c}\text { Testing } \\
\text { Parameter }\end{array}$ & $\begin{array}{l}\text { Grid No. } 1 \\
(3.9 \mathrm{M})\end{array}$ & $\begin{array}{c}\text { Grid No. } 2 \\
(4.63 \mathrm{M})\end{array}$ & $\begin{array}{c}\text { Grid No. } 3 \\
(5.84 \mathrm{M})\end{array}$ & $\begin{array}{c}\text { Grid No. } 4 \\
\text { (7.19 M) }\end{array}$ & $\begin{array}{c}\text { Grid No.5 } \\
(7.8 \mathrm{M})\end{array}$ & $\begin{array}{c}\text { Grid No.6 } \\
(8.1 \mathrm{M})\end{array}$ \\
\hline Head (m) & 6.3 & 7.53 & 8.26 & 9.2 & 9.21 & 9.19 \\
\hline
\end{tabular}

Table 2. Selected grid details for each PAT component.

\begin{tabular}{ccccc}
\hline Grid Details & Inlet Pipe & Impeller & Guide Vanes & Outlet Pipe \\
\hline Grid type & Hexahedral & Tetrahedral & Hexahedral & Hexahedral \\
Grid number (Million) & 1.2 & 2.51 & 2.17 & 1.31 \\
Orthogonal Quality (0-1) & 0.45 & 0.32 & 0.4 & 0.4 \\
Skewness (0-1) & 0.45 & 0.3 & 0.4 & 0.35 \\
\hline
\end{tabular}

\subsection{Numerical Simulation Scheme}

The water flow that passes through a PAT's full computational domain is three dimensional. This study considers the working fluid as the water at $25^{\circ} \mathrm{C}$. It is considered incompressible, isothermal, and is governed by the Reynolds-averaged Navier-Stokes equations, otherwise known as RANS. The RANS-associated continuity and momentum equations are shown in Equations (1) and (2).

Continuity equation:

$$
\frac{\partial}{\partial x_{i}}\left(\rho u_{i}\right)=0
$$

Momentum equation:

$$
\frac{\partial}{\partial t}\left(\rho u_{j}\right)+\frac{\partial}{\partial x_{j}}\left(\rho u_{j} u_{i}\right)=-\frac{\partial p}{\partial x_{j}}+\frac{\partial \tau_{i j}}{\partial x_{j}}+S_{i j}
$$

In these equations, $u_{i}$ and $u_{j}$ stand for velocity components, $\tau_{i j}$ stand for shear stress, $S_{i j}$ for the source term, $p$ for pressure, and $\rho$ for density. In this study, the shear stress transport (SST) computational model was selected for the closure of the RANS equations [56]. This model combines the advantages of the renowned $k-\varepsilon$ and $k-\omega$ models $[57,58]$, thus giving it superiority over both of them. This is due to its ability to deliver high-accuracy predictions for flow dynamics in the wall vicinities and flow zones away from it, especially when solving for study cases involving adverse pressure gradients and flow separations [59]. Equations (3)-(5) are the mathematical expressions of SST's turbulent kinetic energy, its specific dissipation rate, and the kinematic eddy viscosity, respectively.

$$
\frac{\partial k}{\partial t}+u_{j} \frac{\partial k}{\partial x_{j}}=P_{k}-\beta^{*} k \omega+\frac{\partial}{\partial x_{j}}\left[\left(v+\sigma_{k} v_{T}\right) \frac{\partial k}{\partial x_{j}}\right]
$$




$$
\begin{gathered}
\frac{\partial \omega}{\partial t}+u_{j} \frac{\partial \omega}{\partial x_{j}}=\alpha S^{2}-\beta \omega^{2}+\frac{\partial}{\partial x_{j}}\left[\left(\nu+\sigma_{\omega} \nu_{T}\right) \frac{\partial \omega}{\partial x_{j}}\right]+2\left(1-F_{1}\right) \sigma_{\omega, 2} \frac{1}{\omega} \frac{\partial k}{\partial x_{i}} \frac{\partial \omega}{\partial x_{i}} \\
v_{T}=\frac{a_{1} k}{\max \left(a_{1} \omega, S F_{2}\right)}
\end{gathered}
$$

The 3D numerical simulation of PAT flow under different operating conditions is conducted using the CFD's commercial code Ansys CFX 18.0. Simulations were set in such a way that the water flow entered the computational domain at the inlet zone of the inlet pipe (see Figure 1), then passed through the guide vanes inter-spaces before whirling through the impeller inter-blade channels, and flowed down to the outlet pipe to finally exit the computational domain through the outlet pipe's outlet zone.

For the sake of a quick solution convergence, steady state numerical simulations were initially run, where their results files served the initial states for the followed transient simulations. A constant mass flow $\left(\mathrm{kg} \mathrm{s}^{-1}\right)$ was imposed at the inlet of the computational domain as the inlet boundary condition, while a gauge pressure $(\mathrm{Pa})$ was selected as the outlet boundary conditions. Different interfaces were utilized between components of the computational domain, depending on the location and simulation type. The frozen rotor interface was used at both ends of the impeller under steady state numerical simulations, while it was changed to transient rotor-stator interface for transient numerical simulations. The general grid interface (GGI) was used between the stationary components for both simulation types. All the remaining solid walls were given a non-slip boundary condition.

The length of a single simulation session was set to ten impeller revolutions, where the selected timestep $(\Delta t)$ was equivalent to the impeller's one degree rotation $\left(1^{\circ}\right)$, which therefore means that a single impeller revolution was equivalent to $360 \times \Delta \mathrm{t}$. Five internal loops were selected for each timestep. The solution convergence criteria was chosen as the root mean square of residuals inferior to $1 \times 10^{-4}$. For the sake of checking the trustworthiness of generated simulation results by the above-presented numerical scheme, experimental and numerical simulation results in terms of machine external performance characteristics were compared.

Experiments were conducted on a PAT test rig, as shown in Figure 3. In this figure, the test rig components are shown on the right side, and their respective positions on a fully assembled PAT system are shown by letters A, B, and C. The test rig had the highest head $(\mathrm{H})$ and flow rate $(\mathrm{Q})$ of $100 \mathrm{~m}$ and $1000 \mathrm{~L} / \mathrm{s}$, respectively. The adoptable impeller speed range was 0 to $1500 \mathrm{rpm}$, which could accommodate impeller diameters in the range from 250 to $460 \mathrm{~mm}$.
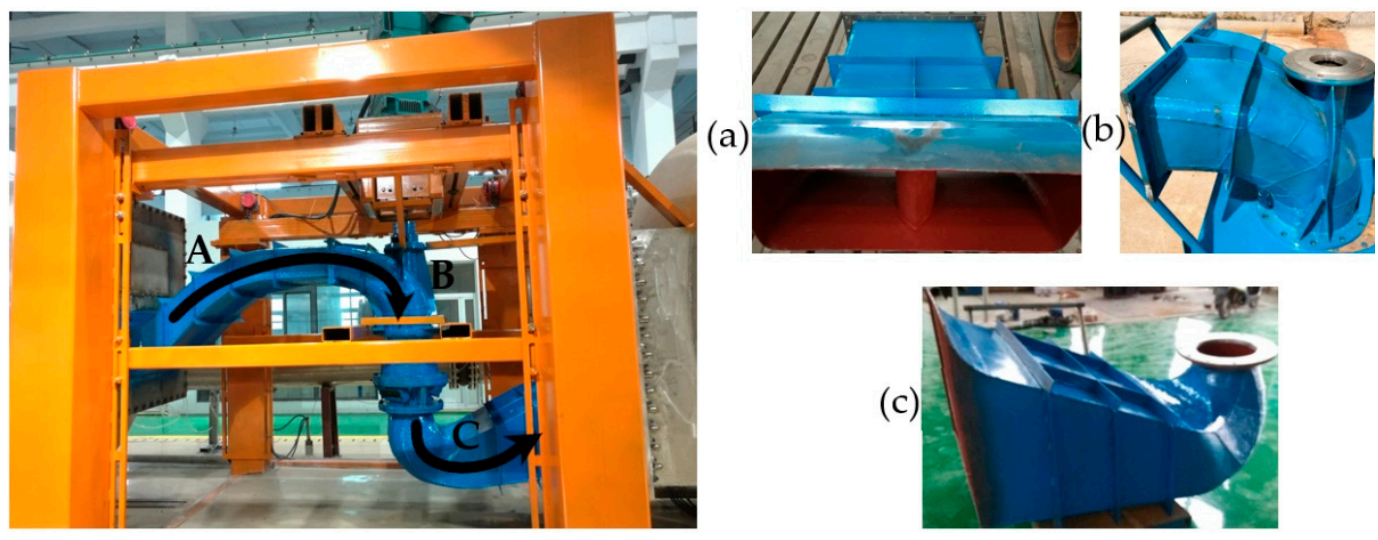

Figure 3. PAT Experimental test rig and components (a) Inlet pipe (b) Shaft casing (c) Outlet pipe.

As shown in Figure 4, a global error of less than $8 \%$ and $6.5 \%$ for head and efficiency predictions was recorded, respectively. The overestimation of experimental results by the utilized numerical scheme is believed to take source for different reasons, including the computational geometry simplification, among others. Nevertheless, the utilized 
numerical scheme showed the ability to generate reasonably accurate results, thus proving its trustworthiness.
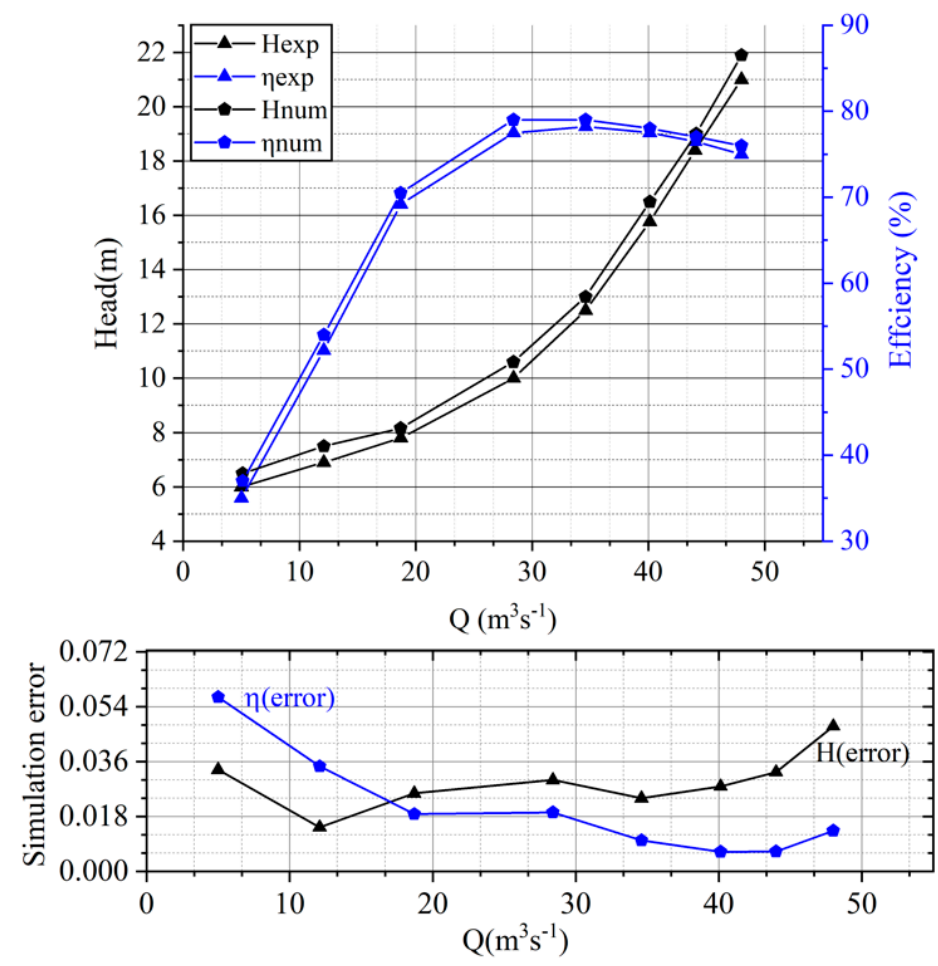

Figure 4. Comparison of test and numerical results.

\section{Results}

\subsection{Flow Field Characteristics Evolution within the Impeller and Guide Vanes}

Though the experimental tests were conducted on a wide range of flows, this study has only considered four operating conditions, namely $1 \mathrm{Q}_{\mathrm{BEP}}, 0.82 \mathrm{Q}_{\mathrm{BEP}}, 0.74 \mathrm{Q}_{\mathrm{BEP}}$, and $0.55 \mathrm{Q}_{\mathrm{BEP}}$, considering a constant impeller rotational speed of $150 \mathrm{rpm}$. This was carried out with a target of investigating the eventual changes in machine flow dynamics for a gradually decreasing machine influx. To do so, three consecutive and equidistant turbosurfaces were selected in the streamwise direction from the impeller inlet to the outlet.

Considering the impeller inlet and outlet positions as 0 and 1, respectively, the 1st plane (S1) was at 0.2, the 2nd (S2) at 0.5, and the 3rd (S3) at 0.8. Each of the three planes expanded from the impeller hub to the shroud. During the investigation of local flow parameter, changes took place as the machine flow rate decreased, and the above-mentioned surfaces were taken as the reference flow zones within the impeller. In this respect, an attempt was completed to showcase some of these changes through both Figures 5 and 6.

Figure 5 shows the pressure distribution mode and associated flow pattern within the impeller flow zone under $0.55 \mathrm{Q}_{\mathrm{BEP}}$. In this figure, from left to right, are plane S3 (impeller outlet vicinal zone), plane S2 (impeller most central zone), and plane S1 (impeller inlet vicinal zone).

It can be seen that the flow region in the vicinities of the impeller inlet (Plane S1) was marked by considerably low-pressure zones on the blade pressure side and highpressure zones on the blade's suction side. This, as confirmed by Figure $5 b$, is linked to the occurred flow separations on the blade pressure side around the blade leading edge under this condition. However, low-pressure zones and corresponding flow separations weakened in the downstream direction. The evolution of local pressure distribution mode, and associated flow structures as the machine influx decreased, are presented in Figure 6. In this figure, the selected plane is S2 which is, as already mentioned, located in the impeller's most central zone (blade mid-length zone). As presented in Figure 6 left side, high-pressure zones were located on the blade pressure surface (BPS) in the vicinal flow 
zones of the impeller shroud. On the other hand, low-pressure zones were located on each blade's suction side (BSS), in the shroud's vicinal flow zones.
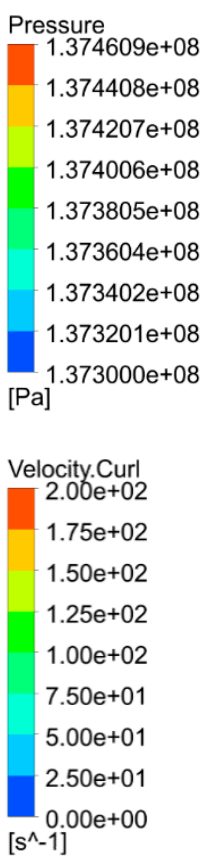
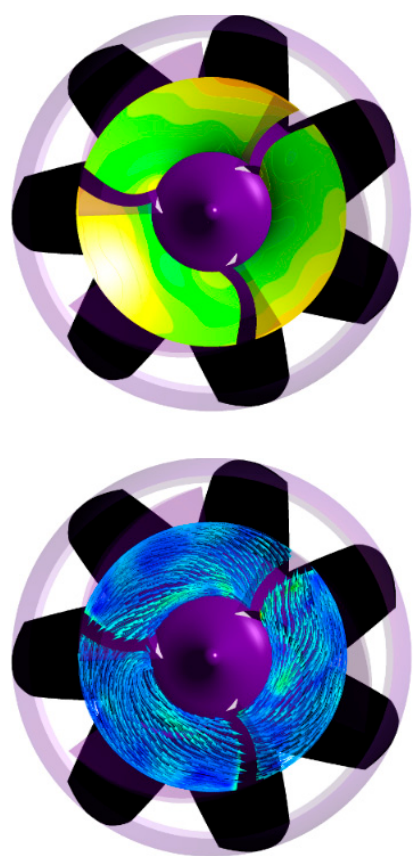

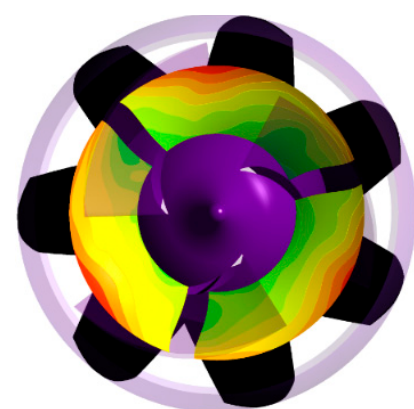

(a)

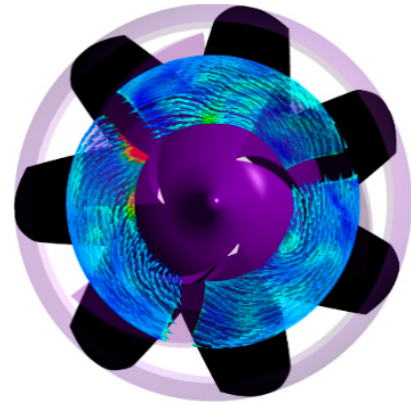

(b)
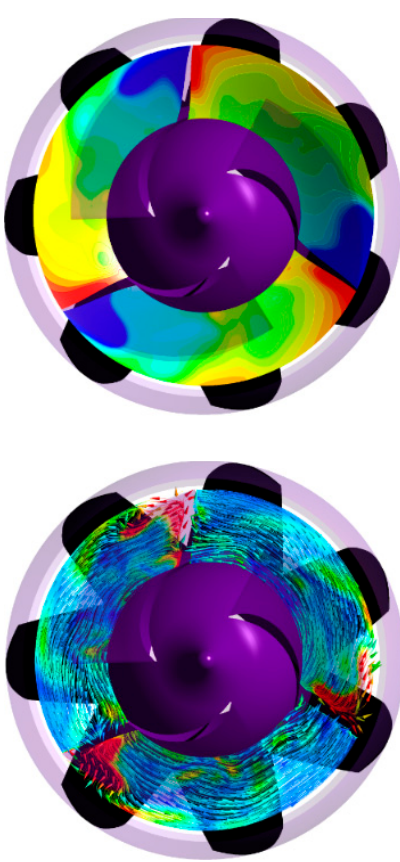

Figure 5. Impeller flow field characteristics at different planes in the streamwise direction for 0.55 Q $\mathrm{BEP}$ condition (a) pressure distribution contours (b) velocity curl-colored flow streamlines.
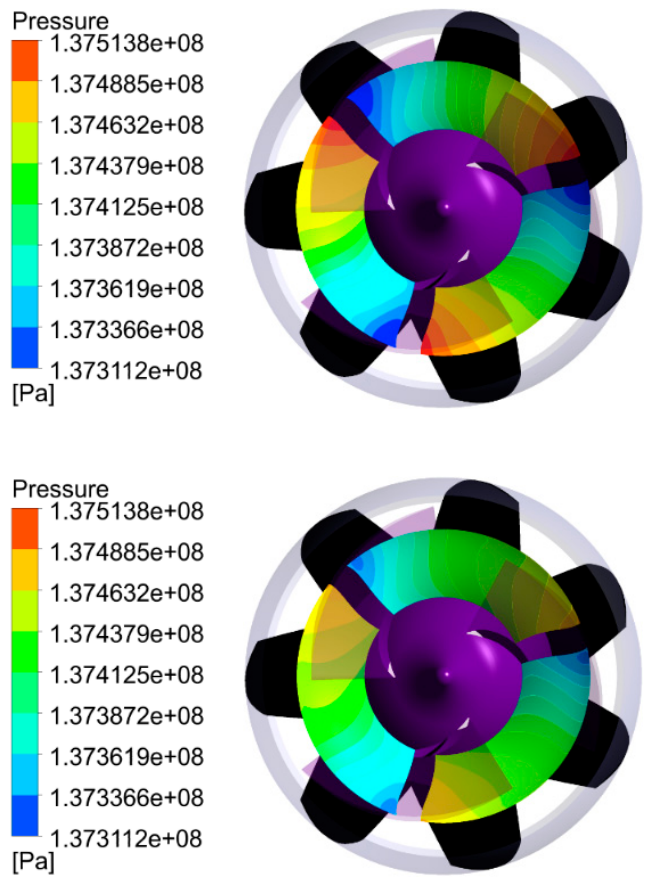

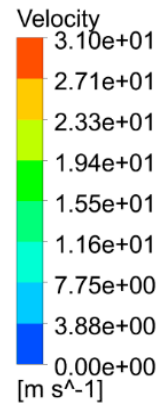

(a)

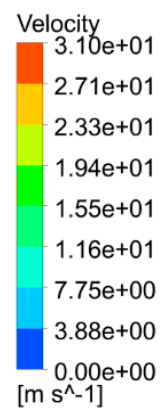

(b)
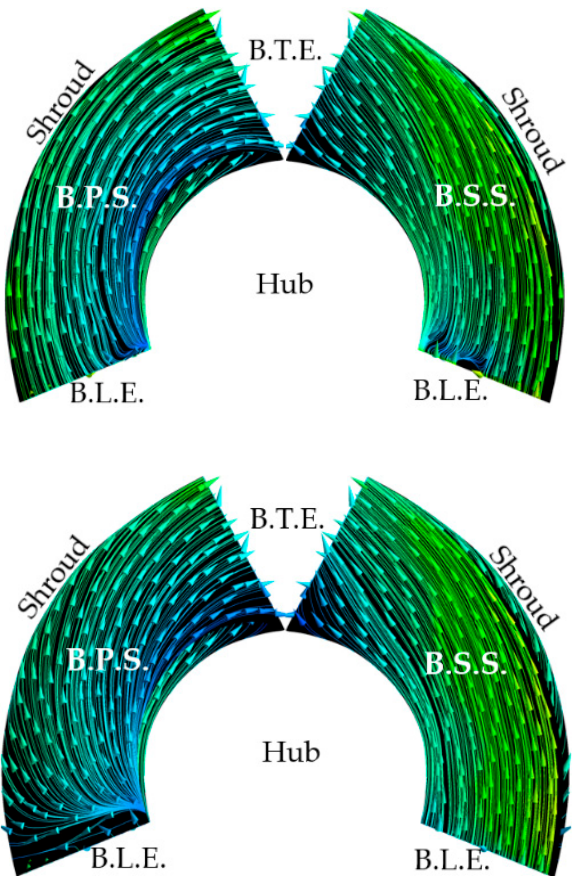

Figure 6. Cont. 

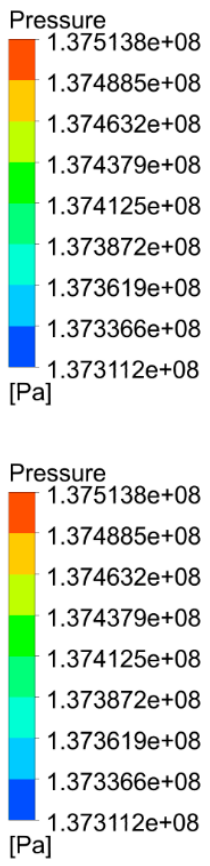
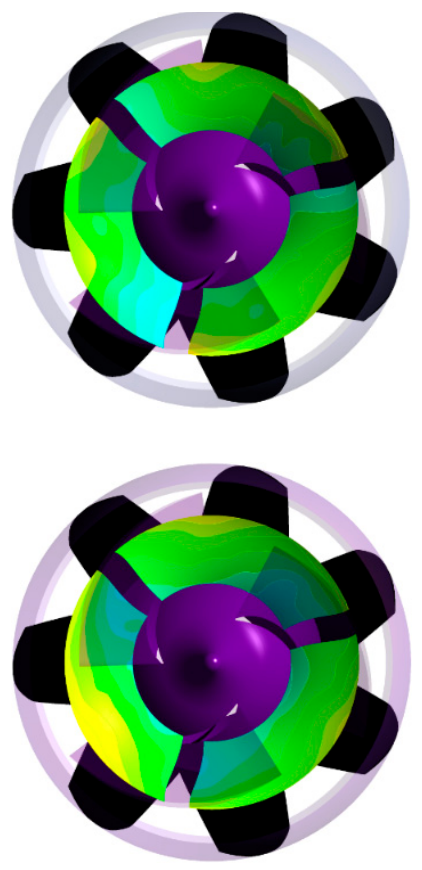

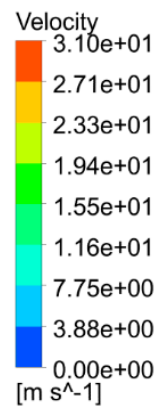

(c)

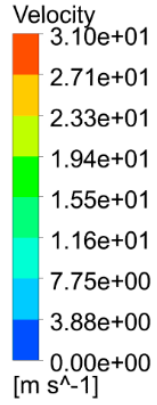

(d)
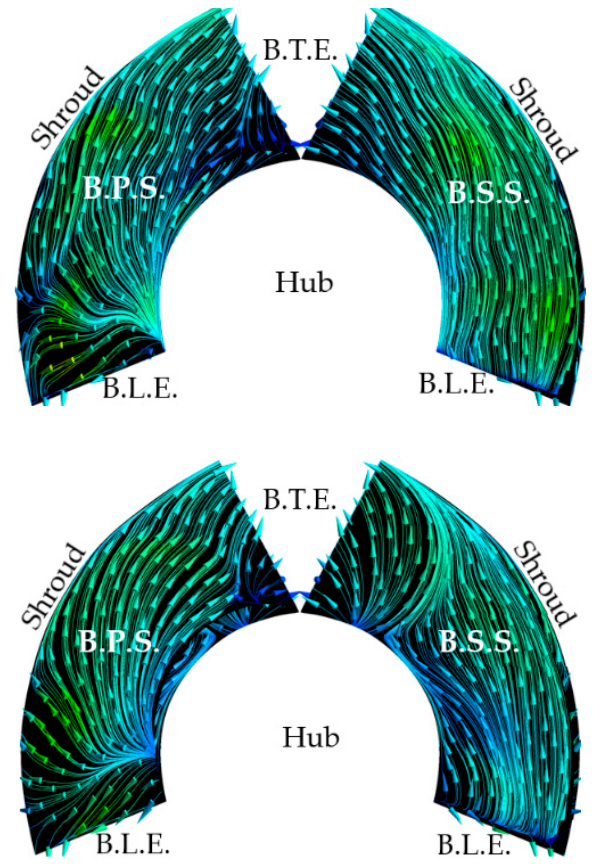

Figure 6. Evolution of Impeller flow field characteristics (a) $1.00 \mathrm{Q}_{\mathrm{BEP}}$ (b) $0.82 \mathrm{Q}_{\mathrm{BEP}}$ (c) $0.74 \mathrm{Q}_{\mathrm{BEP}}$ and (d) $0.55 \mathrm{Q}_{\mathrm{BEP}}$.

With the machine influx decrease from 1.00 $\mathrm{Q}_{\mathrm{BEP}}$ to $0.55 \mathrm{Q}_{\mathrm{BEP}}$, local pressure on the BSS was found to gradually increase, while the BPS pressure correspondingly decreased. The right side of Figure 6 presents the evolution of velocity-colored flow streams on the blade's two surfaces (BPS and BSS). Keeping in mind that the plane in the left hand of Figure 6 was located in the impeller's most central zone, the velocity-colored streams at the same zone showed high and comparatively low speed flows on the BSS and BPS, respectively. This explains the presence of low- and high-pressure zones on respective surfaces, as presented in Figure 6 left side. In addition, the level of flow unsteadiness was found to gradually worsen with the machine influx decrease. Under $0.82 \mathrm{Q}_{\mathrm{BEP}}$ conditions, there was an emergence of flow separations within the vicinal flow zones of the blade leading edge (BLE), especially on the BPS.

Under $0.74 \mathrm{Q}_{\mathrm{BEP}}$ conditions, the area occupied by BLE flow separations widened up, especially in the shroud vicinities, and extended towards downstream, eventually reaching the blade's mid-length zone. In addition, another vortex flow zone appeared at the blade trailing edge (BTE) within the hub region and vicinities. Under this condition, the flow on the BSS also became slightly disturbed, especially in the hug region towards the BTE. Under $0.55 \mathrm{Q}_{\mathrm{BEP}}$ conditions, the BLE flow separation became even wider, while the BTE one almost did not grow. However, flow vortices on the BSS grew far larger, both at the BLE's hub region and the BTE's whole zone from hub to shroud, probably causing the blockage of the flow passage in the blade's vicinal zone. It is therefore obvious that the impeller flow field becomes more and more disturbed with the decreasing machine influx, where flow separations in form of shock and vortical flows emerge and eventually grow. It was found that these secondary flow structures are more likely to take place at the impeller blade's leading edge and flow zones in the vicinities of the impeller shroud, respectively.

As for the flow characteristics in the guide vanes region, Figure 7 shows the eventual changes in local flow structures as the machine influx decreased. The left side shows the velocity-colored streams at different flows. It can be seen that, as is the case with the impeller flow zone, the guide vanes flow pattern becomes messy when the flow rate decreases, and where vortical structures are emerge and eventually grow at certain flow zones, especially the vaneless space zone and the vane pressure side's shroud vicinities. For high-flow conditions (1.00 $\mathrm{Q}_{\mathrm{BEP}}$ and $\left.0.82 \mathrm{Q}_{\mathrm{BEP}}\right)$, flow vortices in shroud vicinities occupy 
a tiny area (D), while flow wakes (E) formed at the vane's trailing edge expand to the vaneless space.
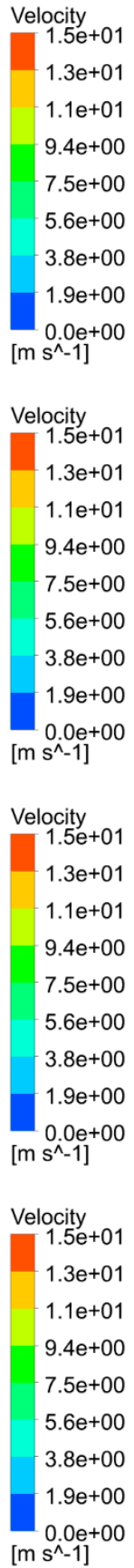
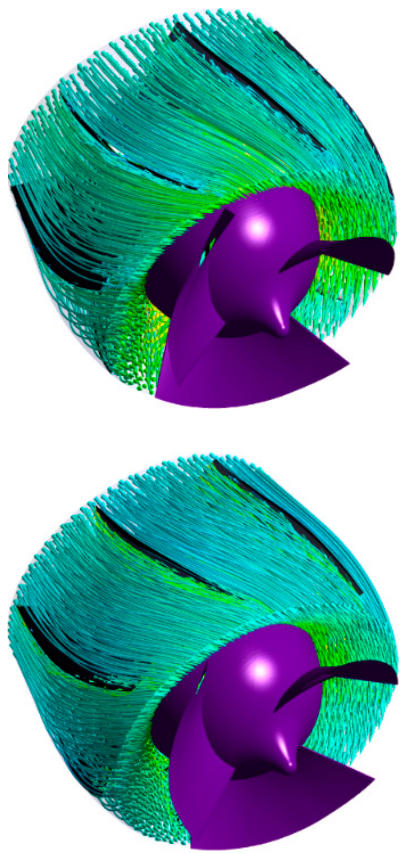

(b)

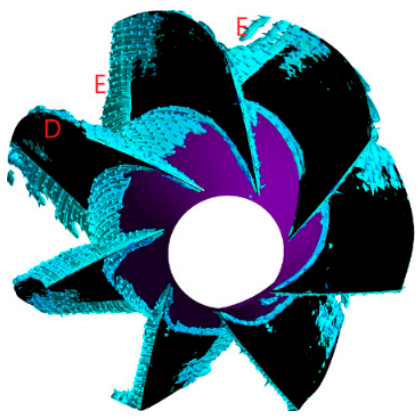

(a)
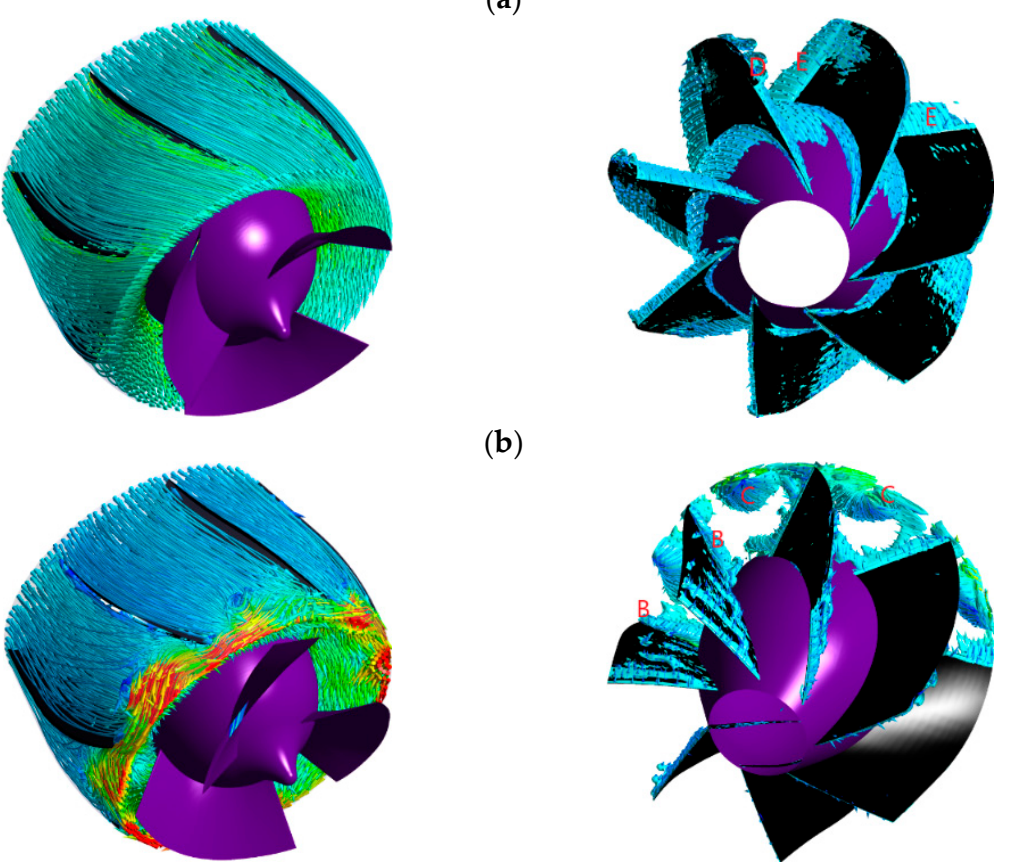

(c)
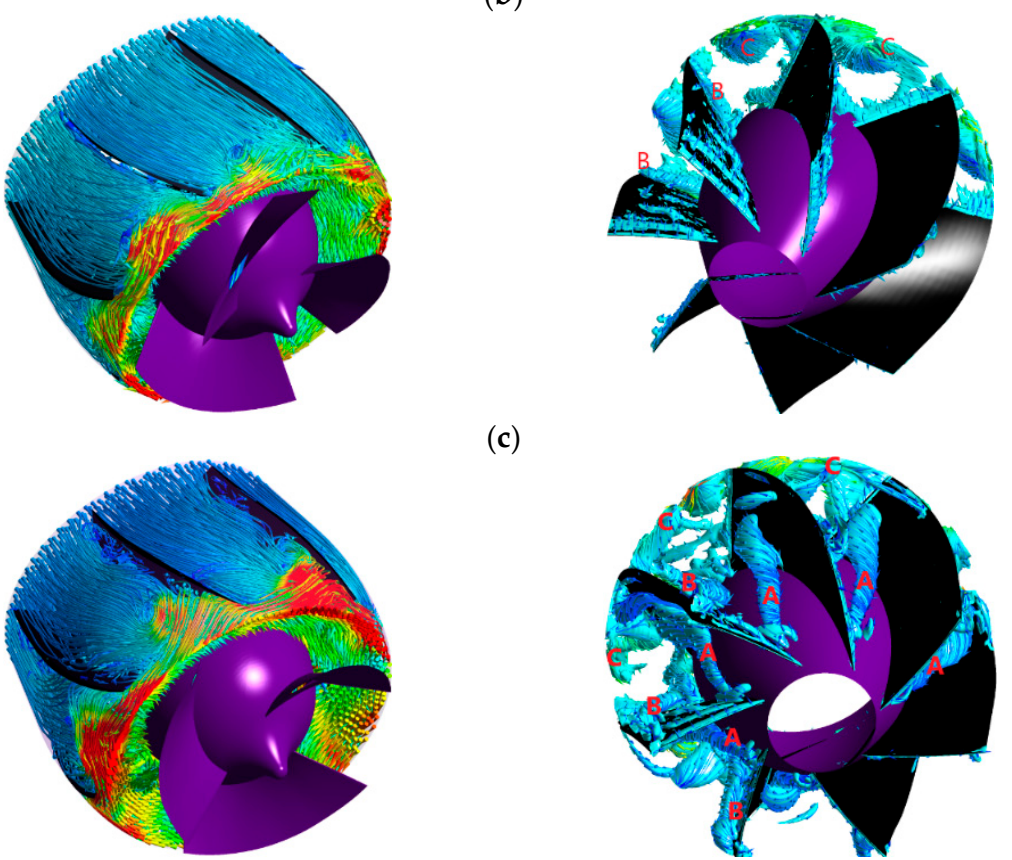

(d)

Figure 7. Guide vane flow structures evolution for different operating conditions (a) 1 QBEP, (b) $0.82 \mathrm{Q}_{\mathrm{BEP}}$, (c) $0.74 \mathrm{Q}_{\mathrm{BEP}}$, and (d) $0.55 \mathrm{Q}_{\mathrm{BEP}}$.

Under $0.74 \mathrm{Q}_{\mathrm{BEP}}$, there was a new tubular vortex that emerged in the vicinity of the guide vane trailing edge, expanding spanwise from hub to the shroud side (B). In addition, another vortex structure appeared near the guide vane's outlet zone, within the guide vane shroud region $(C)$. Under deep part-load condition $\left(0.55 \mathrm{Q}_{\mathrm{BEP}}\right)$, type $\mathrm{C}$ vortex grew even larger, occupying the flow zones in the layer below, while type B grew bigger and slightly shifted its location towards upstream zones. In addition, a new and large vortical structure (A) developed from the guide vane's leading edge on its suction side, and travelled 
downstream obliquely, finally touching the next vane's pressure side in the vicinities of its trailing edge. The Type A vortex occurred mostly within the hub region.

It can therefore be briefly concluded that the guide vane flow pattern deteriorates with the decreasing flow where most of vortical structures form in the close proximity of the vaneless space.

\subsection{Effect of Impeller Rotational Speed Variation}

In line with this study's main objectives, an effort was also made to investigate the effect of impeller rotational speed variation on the above discussed PAT flow dynamics under part-load conditions. In this respect, $0.74 \mathrm{Q}_{\mathrm{BEP}}$ was selected as the tested part-load flow condition where five impeller rotational speed ranging from 110 to $190 \mathrm{rpm}$ were considered. For the sake of investigating the occurred changes in impeller flow field characteristics as its rotational speed increased, a mid-span plane $(\mathrm{Span}=0.5)$ was taken as a reference flow zone.

Figure 8 displays the evolution of local pressure distribution within the impeller, as the impeller rotational speed gradually increased. It is generally found that low-pressure zones are located on BLE's pressure side and BSS towards the trailing edge. With a continuously increasing impeller rotational speed, low-pressure zones grew increasingly larger at both mentioned zones, leading to a $190 \mathrm{rpm}$ situation where they can then obviously extend to the draft tube flow zone (adjacent flow zone). In addition, high-pressure zones are found to be on the BLE's suction side and continuously enlarge within the increase in impeller rotational speed.

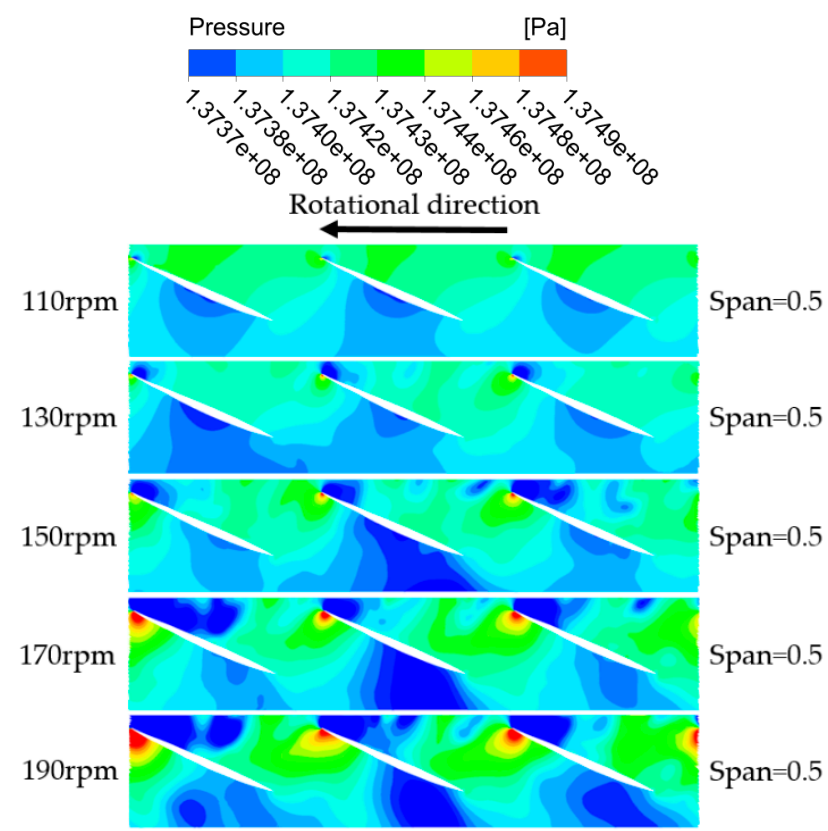

Figure 8. Local pressure variation with the impeller rotating speed under $0.74 \mathrm{Q}_{\mathrm{BEP}}$ flow condition.

In Figure 9, velocity-colored flow streamlines and correspondent turbulence kinetic energy distribution on the BPS are presented. Having considered a part-load condition $\left(0.74 \mathrm{Q}_{\mathrm{BEP}}\right)$, the above-discussed flow separations were already present for the lowest of five tested speed values (110 rpm). Those were the BLE's pressure side shock flow, its extension downstream in shroud vicinities, and the BTE's hub vortex. With the increasing impeller rotational speed, the above-cited vortical structures strengthened and occupied even wide areas. This aspect is confirmed through Figure 9 right side where the evolution of BPS turbulence kinetic energy with the increasing speed is presented. It is shown that a high-BPS turbulence kinetic energy zone was located at the BLE close to the shroud under $110 \mathrm{rpm}$ condition. 


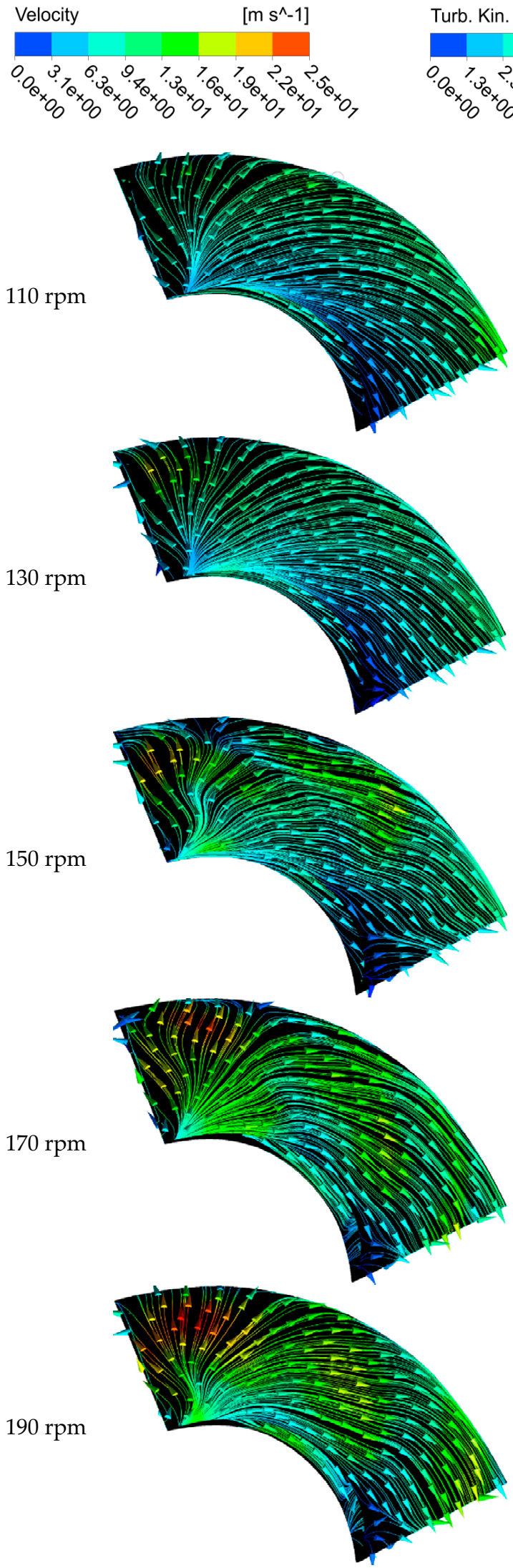

(a)
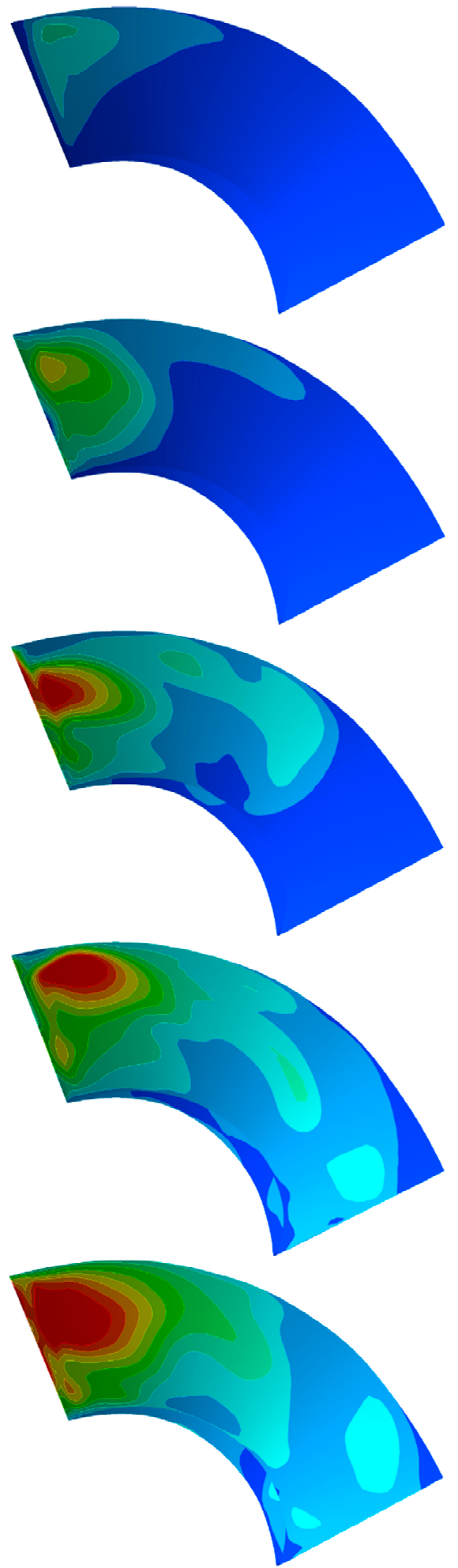

(b)

Figure 9. Variation in flow patterns under 0.74 $\mathrm{Q}_{\mathrm{BEP}}$ operating condition (a) BPS velocity-colored flow streamlines (b) BPS turbulence kinetic energy contours. 
With the increasing rotational speed, this zone gradually widened up in both the spanwise and streamwise directions, reaching the blade mid-length zone under $190 \mathrm{rpm}$ condition. It is therefore obvious that, for a PAT already operating under part-load conditions, the increase in impeller rotational speed worsens the level of flow instability.

\subsection{Pressure Pulsation Characteristics}

In order to study the evolution of pressure pulsation characteristics and its distribution mode for the above-discussed operating conditions, different flow zones were selected, at which pressure-monitoring points were positioned. To be more specific, nine pressure monitors were positioned on the mid-span plane of the inter-blade flow zone, as shown in Figure 10a. In addition, considering three consecutive span-wise planes from hub to the shroud, 18 monitors were positioned on the BPS, where each of the planes held six equidistant monitors expanding from the blade's leading edge to the trailing edge as shown in Figure $10 \mathrm{~b}$.

(a)

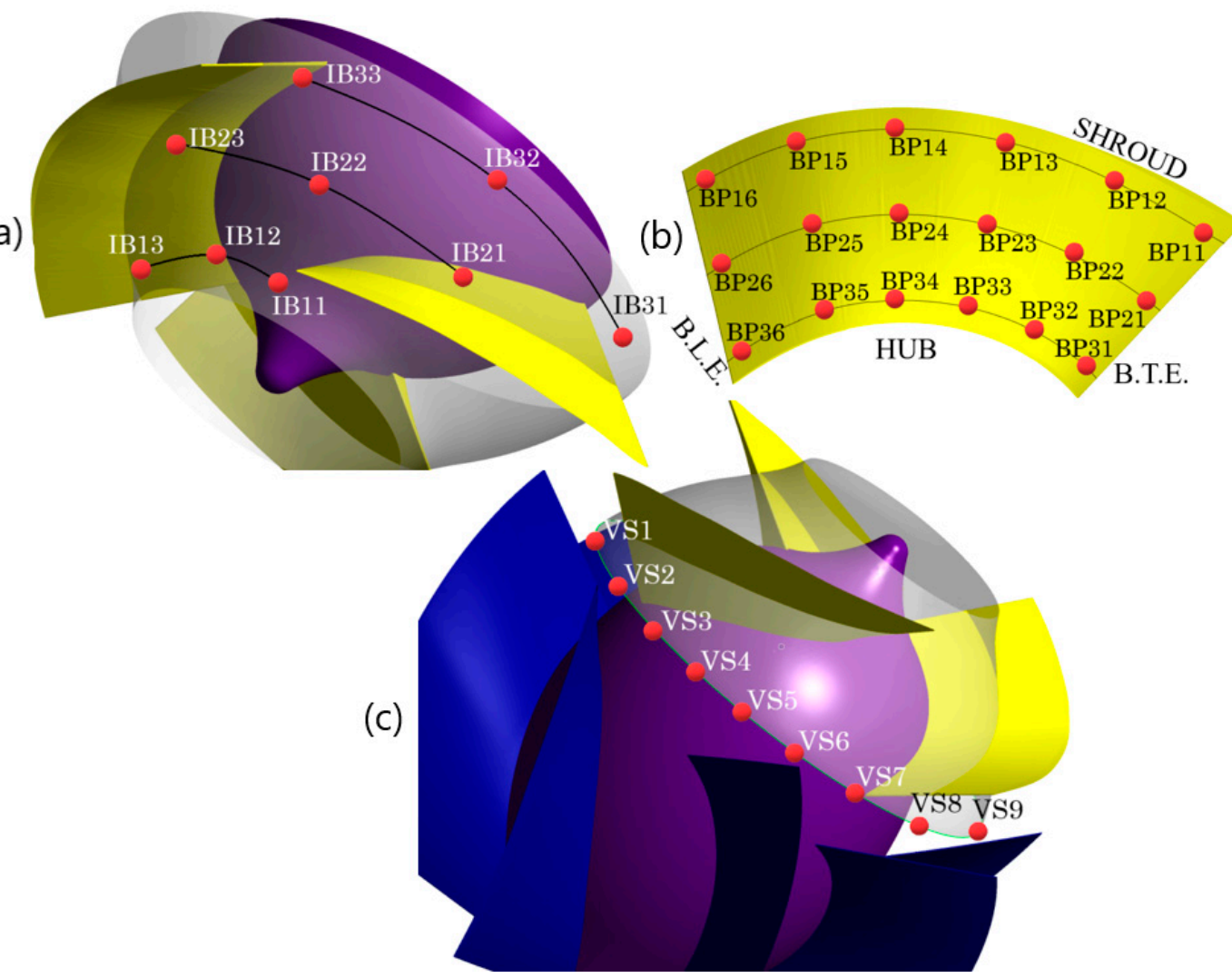

Figure 10. Pressure monitoring point locations. (a) Inter-blade channel (b) Blade pressure side and (c) Vaneless space.

Six monitors, BP16 to BP11, were located within the shroud's vicinal zone. The other six, BP26 to BP21, were positioned on the mid-span plane, and the last six were located in the hub's vicinal zone. Finally, 24 equidistant monitors were positioned around the whole vaneless space between the impeller and the guide vanes as shown in Figure 10c.

Figure 11 shows the pressure pulsation characteristics in the vaneless space zone for the four investigated flow conditions. The VS pressure pulsation spectra were found to be dominated by $7 \mathrm{fn}$ component for both BEP and $0.82 \mathrm{Q}_{\mathrm{BEP}}$ conditions ( $f n$ : impeller rotational frequency). 


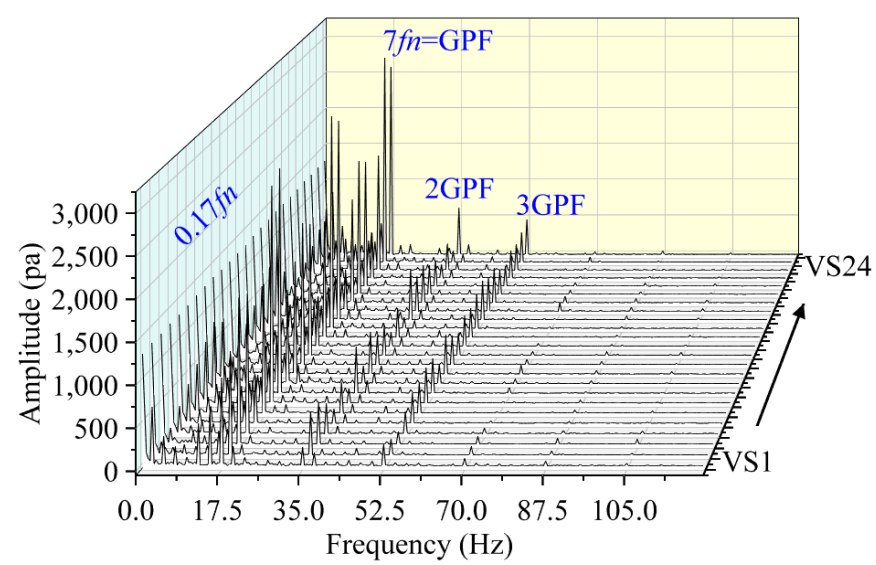

(a)

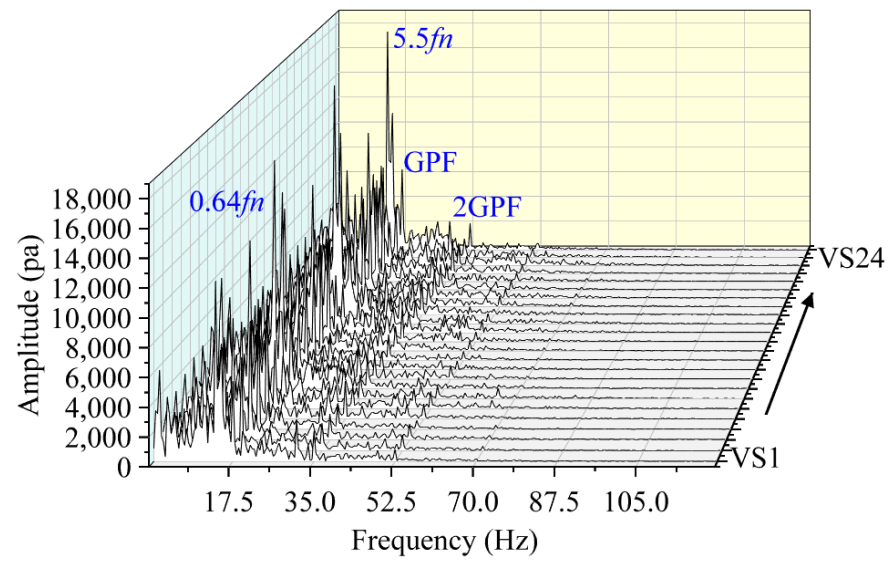

(c)

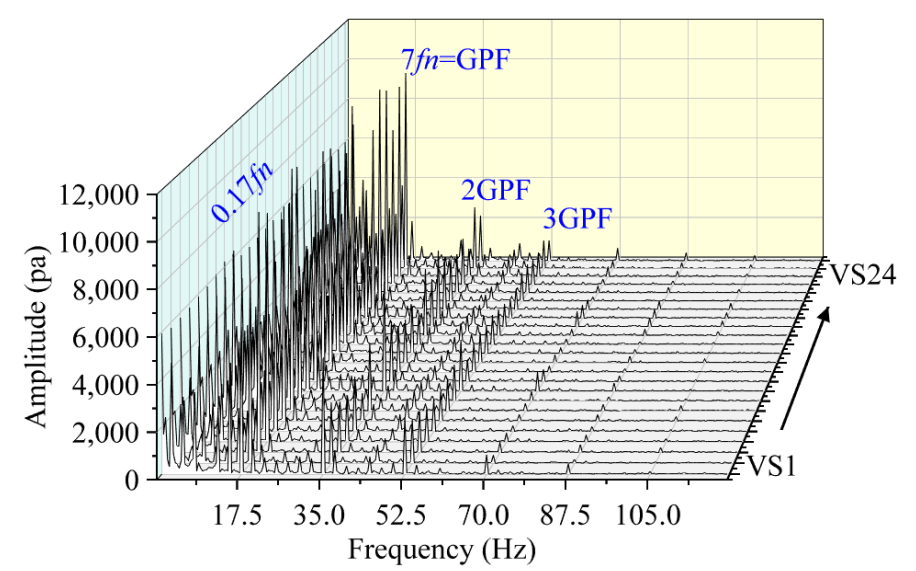

(b)

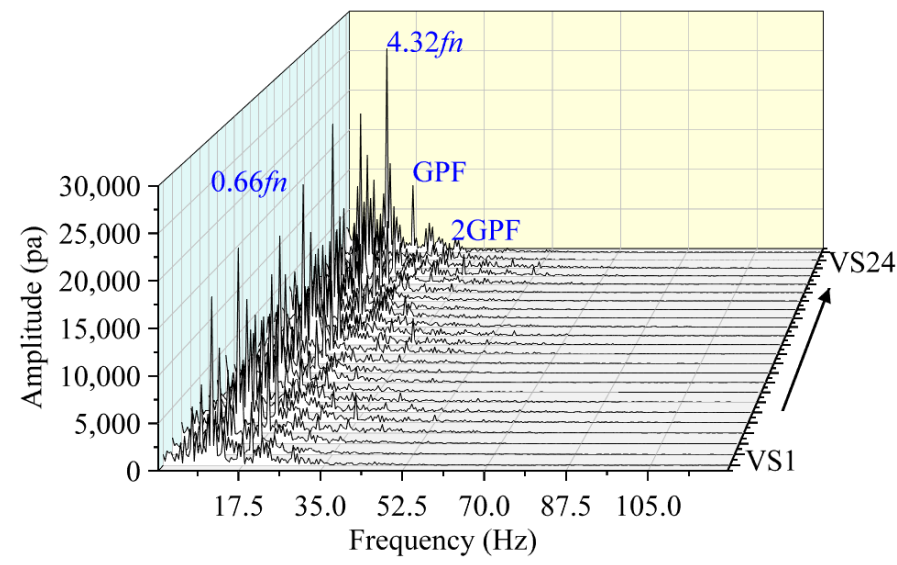

(d)

Figure 11. Vaneless space pressure pulsation spectra under different flow conditions (a) $1.00 \mathrm{Q}_{\mathrm{BEP}}$ (b) $0.82 \mathrm{Q}_{\mathrm{BEP}}$ (c) $0.74 \mathrm{Q}_{\mathrm{BEP}}$ and (d) $0.55 \mathrm{Q}_{\mathrm{BEP}}$.

Considering the impeller rotational speed of $150 \mathrm{rpm}$, this component represented the effect of rotor-stator interaction (RSI), known as the guide vane passing frequency $\left(\mathrm{GPF}=\mathrm{Z}_{\mathrm{G}} \times f n\right)$. Under BEP conditions, the VS pressure pulsation spectrum was marked by GPF as the 1st dominant frequency, followed by a low-frequency component (LFC) $0.17 \mathrm{fn}$. Moreover, more LFCs, which are multiples of $f n$, emerged between these two components (0.17 $f n$ and GPF), adding to GPF harmonics which are considered highfrequency components. When the machine influx decreased from $1.00 \mathrm{Q}_{\mathrm{BEP}}$ to $0.82 \mathrm{Q}_{\mathrm{BEP}}$, the above-described components persisted, but their amplitudes considerably increased, reaching to pulsation amplitude values four times higher.

Considerably remarkable changes in VS pressure pulsation characteristics were again recorded when the machine flow conditions reached $0.74 \mathrm{Q}_{\mathrm{BEP}}$. Under this condition, unlike the first two conditions, the dominant frequency component shifted to LFC class, where $5.5 \mathrm{fn}$ serves as the 1st dominant frequency component, followed by $0.64 \mathrm{fn}$ as the 2nd dominant frequency. The RSI-born components are still present but with comparatively small amplitudes.

It is also worth mentioning that, compared to previous flow conditions, there was a global increase in pressure pulsation amplitudes, and a multitude of more LFCs emerged. This corresponds to increased local flow unsteadiness (LFU), as also discussed in the above sections. Under $0.55 \mathrm{Q}_{\mathrm{BEP}}$ condition, pulsation characteristics from the precedent flow condition persisted where, however, pulsation amplitudes continued to grow, and the 1st dominant frequency shifted to $4.32 \mathrm{fn}$, which is still classified as the LFC, while $0.66 \mathrm{fn}$ served the 2nd dominant frequency. 
In brief, the vaneless space pressure pulsation characteristics were found to be consistent with PAT flow dynamics evolution as the machine influx decreased. Under the first two high flow conditions, PAT flow experienced low-level of unsteadiness. Therefore, correspondent vaneless space pressure pulsation spectra were dominated by RSI-born frequency components.

Moreover, the number of LFCs was still low under these two conditions, which means a low level of local flow instability. On the other hand, the last two low flow conditions were marked by the dominance of LFCs and the increase in their numbers.

Though the RSI-born components were still present, their amplitudes were comparatively very low. This coincides with the increase in local flow unsteadiness under these conditions, where the impact of RSI on VS pressure pulsation characteristics became negligible, as compared to that inflicted by local flow instabilities.

In the same respect, an attempt was made to investigate the evolution of pressure pulsation levels in the vicinities of the impeller blade pressure surface for different flow conditions, as shown in Figure 12. This was performed using the relative pressure pulsation coefficient $C P$, for which the mathematical expression is presented in Equation (6).

$$
C P=\frac{\left(P_{i \max }-P_{i \min }\right)}{\rho g H}
$$

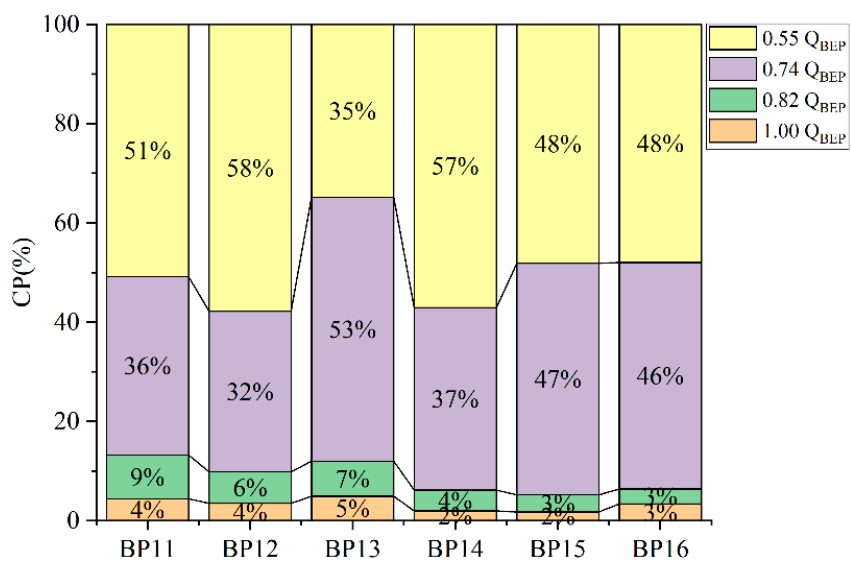

(a)

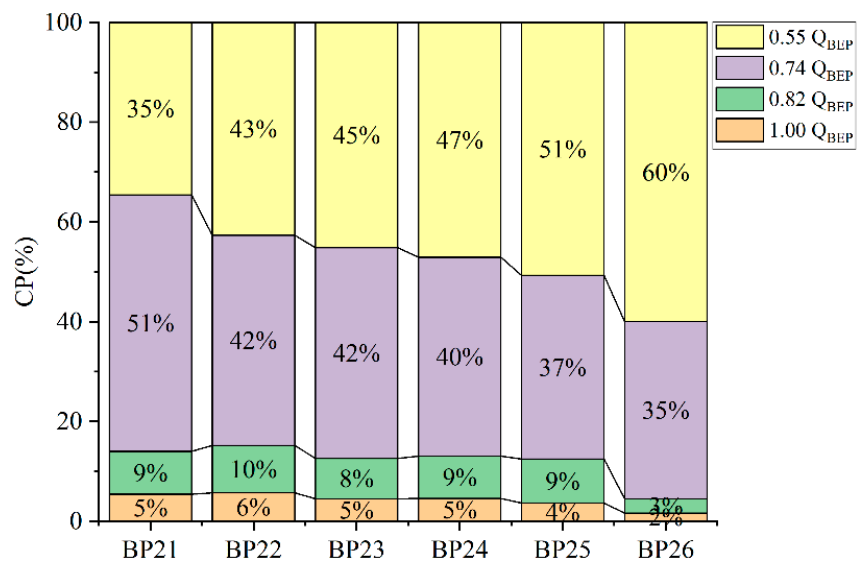

(b)

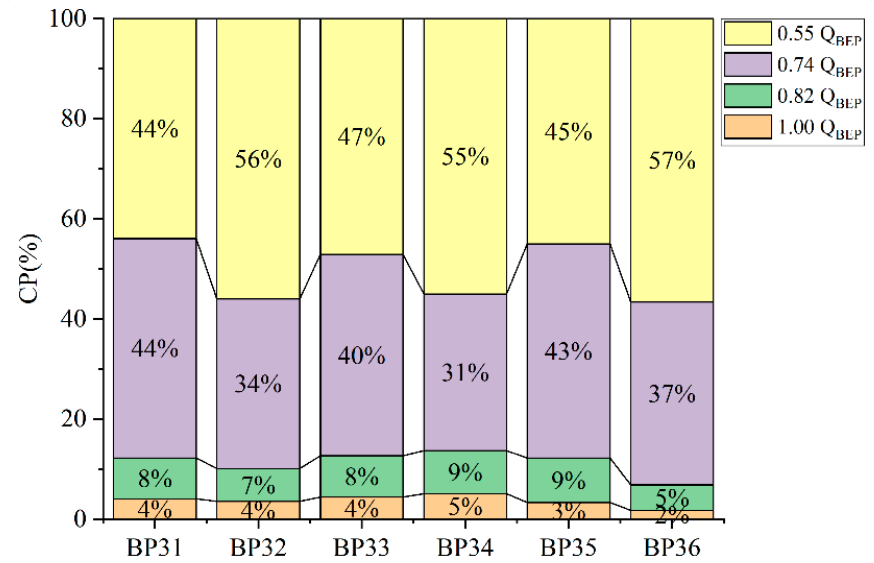

(c)

Figure 12. Pressure pulsation extent in BPS vicinities at three span-wise planes under different flow conditions (a) Shroud vicinal zone (b) Mid-span zone and (c) Hub vicinal zone.

In this formula, $P_{\mathrm{imax}}$, and $P_{\mathrm{imin}}, \rho, g$, and $H$ stand for the individual point's maximum and minimum pressure pulsation amplitudes, fluid density, gravitational acceleration, and 
head, respectively. Figure 12 considers BPS monitoring points as shown in Figure 10b. In this figure, pressure pulsation amplitudes are found to decrease in the streamwise direction from the blade's leading edge (vaneless space vicinities) towards its trailing edge (impeller outlet zone vicinities).

As also discussed in the above sections, it is also shown that the first two high flow conditions (1.00 $\mathrm{Q}_{\mathrm{BEP}}$ and $0.82 \mathrm{Q}_{\mathrm{BEP}}$ ) exhibited the lowest of pressure pulsation levels, while the last two $\left(0.74 \mathrm{Q}_{\mathrm{BEP}}\right.$ and $\left.0.55 \mathrm{Q}_{\mathrm{BEP}}\right)$ were marked by high-pressure pulsation levels. Generally speaking, BPS pressure pulsation levels worsened with the decrease in machine flow conditions.

In the next section, an attempt was made to investigate the evolution in pressure pulsation distribution modes at different PAT flow zones, with the increasing impeller rotational speed, under two operating conditions, namely $1.00 \mathrm{Q}_{\mathrm{BEP}}$ and $0.74 \mathrm{Q}_{\mathrm{BEP}}$. Figure 13 shows the pressure pulsation distribution mode within the vaneless space zone for different speeds, considering the above-mentioned flow conditions.

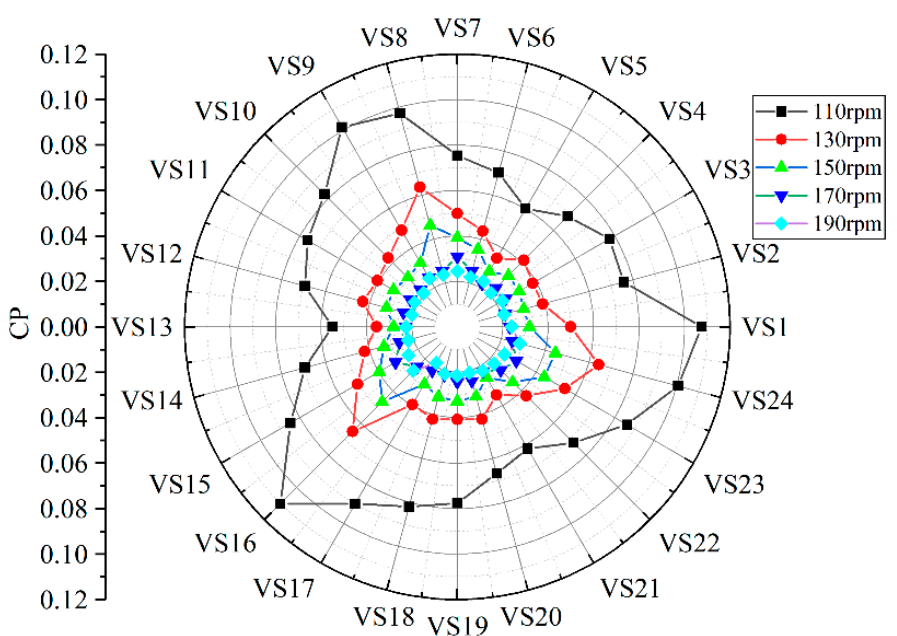

(a)

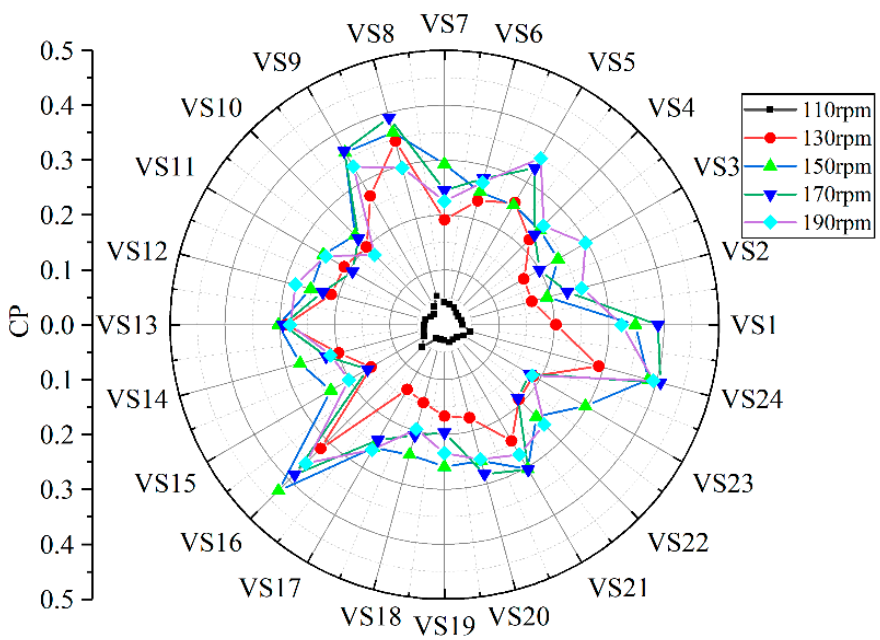

(b)

Figure 13. Vaneless space pressure pulsation distribution mode for different impeller rotational speeds (a) 1.00 Q $\mathrm{BEP}_{\mathrm{B}}$ (b) $0.74 \mathrm{Q}_{\mathrm{BEP}}$.

In this figure, as also explained in the above sections, the VS pressure pulsation level under optimum operating conditions were far lower compared to the $0.74 \mathrm{Q}_{\mathrm{BEP}}$ case. In addition, Figure 13 shows that the impeller rotational speed inflicts opposite reactions from both conditions' VS pressure pulsation characteristics. It is shown that, under optimum operating conditions, the increase in impeller rotational speed leads to correspondingly decreasing vaneless pressure pulsation levels.

On the other hand, under $0.74 \mathrm{Q}_{\mathrm{BEP}}$ conditions, speed increases from 110 to $130 \mathrm{rpm}$ led to the increase in pulsation levels, while the situation was complex for the rest of speeds. The pressure pulsation distribution mode for the rest of speeds $(150,170$, and $190 \mathrm{rpm})$ was quite similar and their amplitudes quite randomly varied, but within short ranges.

Nevertheless, one would globally assume the worsening of pressure pulsation levels with the increase in impeller rotational speed under this condition, which would also be supported by correspondent flow field characteristics evolution, as presented in both Figures 8 and 9 .

In Figure 14, the effect of impeller rotational speed on pressure pulsation distribution mode along PAT's full flow passage is displayed. In the direction of PAT water flow from the computational domain's inlet zone towards the outlet (see Figure 1), different monitoring points were successively positioned along the full flow passage as follows: inlet pipe (OP4, OP33, OP32, and OP31), inter-guide vane channel (GV24, GV23, GV22, 
and GV21), vaneless space zone (VS), impeller inter-blade channel (IB32, IB22, and IB12), and outlet pipe (IP12, IP22, IB32, and IP4).

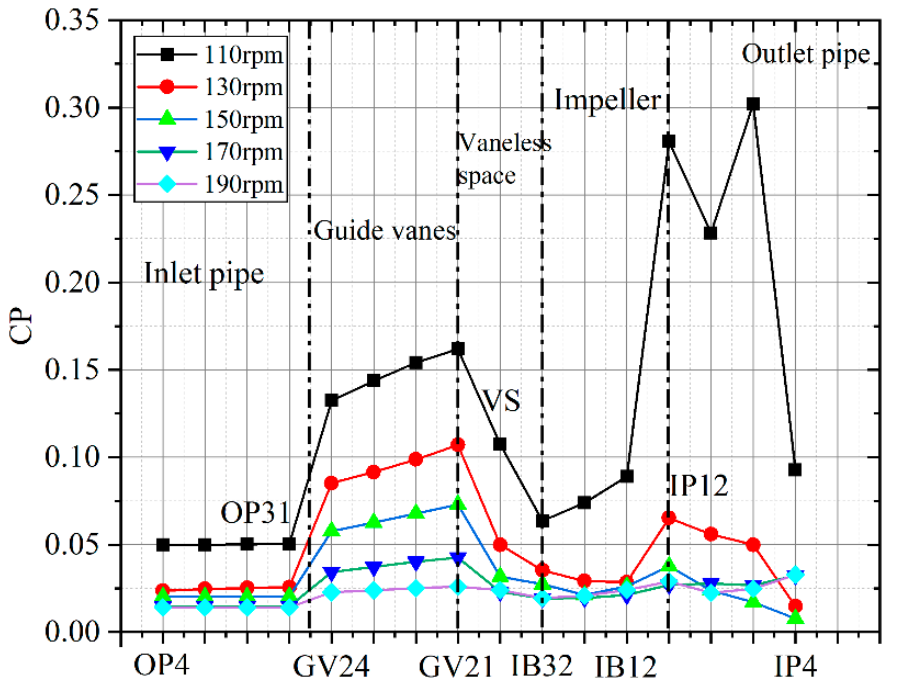

(a)

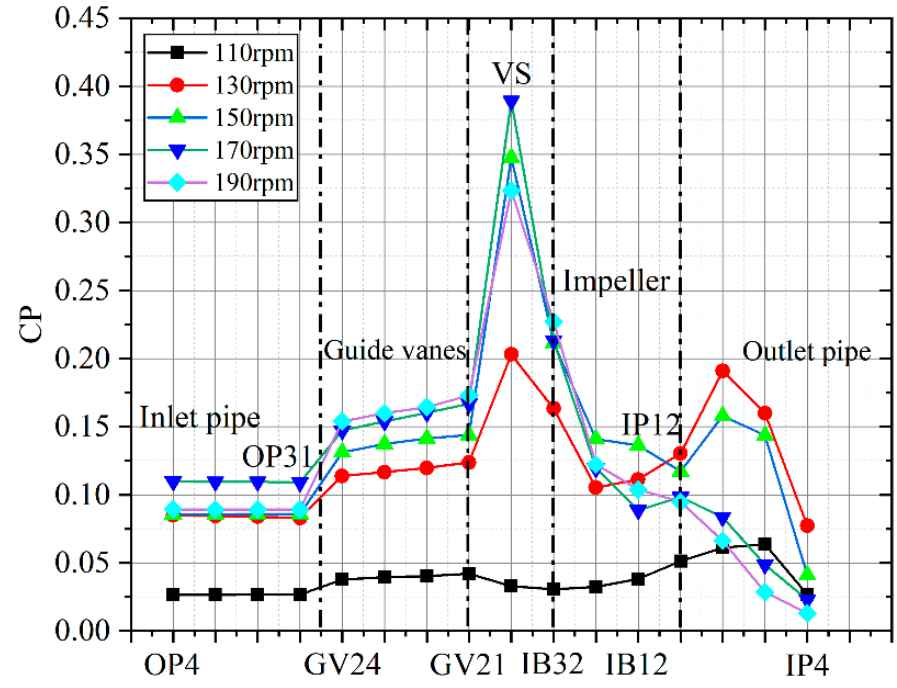

(b)

Figure 14. Pressure pulsation distribution mode along PAT flow passage for different impeller rotational speeds (a) 1.00 Q $\mathrm{Q}_{\mathrm{BEP}}$ (b) $0.74 \mathrm{QBEP}_{\mathrm{BE}}$.

Under optimum operating conditions, pressure pulsation amplitudes within the guide vanes flow zone were globally found to be the highest, with the exception of $130 \mathrm{rpm}$ case where the outlet pipe presented the highest of pressure pulsations. Under this condition, it is again confirmed that the increase in impeller rotational speed led to a global weakening of pressure pulsations along PAT's full flow passage.

Under the $0.74 \mathrm{Q}_{\mathrm{BEP}}$ condition, however, the lowest of pressure pulsations were recorded for $110 \mathrm{rpm}$ cases, followed by $130 \mathrm{rpm}$ for the majority of flow zones. The situation is complex for the rest of speed cases, where, however, unlike the case optimum flow condition case, the highest pressure pulsation level was recorded within the vaneless space.

Therefore, one would globally conclude that, for a PAT under optimum operating conditions, the impeller rotational speed increase would improve the pressure pulsation levels along the machine at full flow passage, while causing an opposite effect for the case of part-load operating conditions.

\section{Conclusions}

This study numerically investigated the evolution of flow dynamics in a mixed-flow PAT under turbine operating mode, and the effect of impeller rotational speed on the same. Four different operating conditions ranging from optimum to part-load flow conditions (1.00 $\mathrm{Q}_{\mathrm{BEP}}, 0.82 \mathrm{Q}_{\mathrm{BEP}}, 0.74 \mathrm{Q}_{\mathrm{BEP}}$, and $0.55 \mathrm{Q}_{\mathrm{BEP}}$ ) were selected, and five impeller rotational speeds ranging from 110 to $190 \mathrm{rpm}$ were tested. After a thorough discussion and deep analysis of study results, a number of concluding remarks were drawn as follows:

With the machine influx decrease from optimum to 0.82 Q $\mathrm{QEP}_{\text {c }}$ condition, PAT flow pattern slightly deteriorated. A further decrease to lower flow conditions inflicted the emergence of very large flow instabilities where, of the four investigated conditions, $0.55 Q_{\text {BEP }}$ presented the least stable flow structures. Moreover, the vaneless space zone between the impeller and guide vanes was found to experience the highest flow unsteadiness under part-load conditions.

Vaneless space pressure pulsation characteristics depended on the machine operating conditions, where pulsation amplitudes continuously increased as the machine influx decreased. For high flow conditions, vaneless space pressure pulsation spectrum was 
dominated by RSI-born frequency components, while the LFU-born frequency components dominated for low flow conditions.

The impeller rotational speed was found to differently impact the machine flow and pressure fields characteristics, depending on the considered operating condition. Under optimum operating conditions, the impeller rotational increase led to a global decrease in pressure pulsations at a majority of flow zones. On the other hand, the increase in impeller rotational speed worsened the pressure pulsation level at different flow zones, under part-load conditions.

It is therefore obvious that the impeller rotational speed exercises a considerable impact of the machine flow and pressure field characteristics, which under certain conditions may end up affecting the overall machine operational efficiency. This, for instance, sends an alert to electric regulation (ER) users within WDNs, where careful impeller rotational speed change is recommended. Further, CFD-supported parametric studies are still needed to reveal the flow dynamics of PATs under turbine mode, and to compare and establish a relationship with the pump mode. This would lead to a complete understanding of PAT flow dynamics, and probably contribute to an improvement in terms of PAT performance prediction accuracy, for the so far existent pump-to-turbine performance conversion expressions.

Author Contributions: Conceptualization, M.B., K.K. and H.-X.C.; Methodology, M.B., H.-X.C., W.-T.S. and X.-F.G.; Software, M.B., K.K., X.-F.G. and J.N.; Formal analysis, M.B., K.K., H.-X.C., Y.Z. and D.-Q.Z.; Writing-original draft, M.B., X.-F.G. and J.N.; Writing-review \& editing, Y.Z., D.-Q.Z., H.-X.C. and K.K.; Resources, K.K., Y.Z. and D.-Q.Z.; Supervision, Y.Z., D.-Q.Z., and K.K.; Funding acquisition, M.B., K.K. and H.-X.C. All authors have read and agreed to the published version of the manuscript.

Funding: This research was funded by the Postdoctoral Research Fund of Jiangsu Province (2020Z152), National Natural Science Foundation of China (52009033; 52006053), Natural Science Foundation of Jiangsu Province (BK20200509; BK20200508), and the Fundamental Research Funds for Central Universities (B210202066).

Institutional Review Board Statement: Not applicable.

Informed Consent Statement: Not applicable.

Data Availability Statement: Not applicable.

Acknowledgments: The support from the College of Water Conservancy and Hydropower Engineering at Hohai University, China is gratefully acknowledged.

Conflicts of Interest: The authors declare no conflict of interest.

\author{
Nomenclature \\ PAT Pump as Turbine \\ RANS Reynolds Averaged Nevier-Stokes equations \\ BEP Best Efficiency Point \\ SST Shear Stress Transport turbulence model \\ IRS Impeller Rotational Speed \\ GGI General Grid Interface \\ VS Vaneless Space \\ LFC Low Frequency Component \\ CFD Computational Fluid Dynamics \\ TRL Technology Readiness Level \\ HR Hydraulic Regulation \\ LFU Local Flow Unsteadiness \\ GPF Guide vane Passing Frequency \\ RSI Rotor-Stator Interactions
}




$\begin{array}{ll}\text { ER } & \text { Electric Regulation } \\ \text { BLE } & \text { Blade Leading Edge } \\ \text { BPS } & \text { Blade Pressure Surface } \\ \text { BTE } & \text { Blade Trailing Edge } \\ \text { BSS } & \text { Blade Suction Surface } \\ \text { GV } & \text { Guide Vane } \\ \text { WDN } & \text { Water Distribution Networks } \\ \text { GSS } & \text { Guide vane Suction Surface } \\ \text { IEC } & \text { International Electrotechnical Commission } \\ \text { GPS } & \text { Guide vane Pressure Surface } \\ \text { IP } & \text { Inlet Pipe } \\ \text { OP } & \text { Outlet Pipe } \\ \text { VOS } & \text { Variable Operating Strategy } \\ \text { PRV } & \text { Pressure Relieve Valve } \\ \text { y+ } & \text { Dimensional height from the wall } \\ f n & \text { Runner rotational frequency } \\ Q & \text { Discharge } \\ n & \text { Runner rotational speed } \\ H & \text { Head } \\ g & \text { Gravitational acceleration } \\ \eta & \text { Efficiency } \\ \mathrm{P} & \text { Static pressure } \\ \rho & \text { Density } \\ Z_{\mathrm{R}} & \text { Number of runner blades } \\ Z_{\mathrm{G}} & \text { Number of guide vanes }\end{array}$

\section{References}

1. Algieri, A.; Zema, D.A.; Nicotra, A.; Zimbone, S.M. Potential energy exploitation in collective irrigation systems using pumps as turbines: A case study in Calabria (Southern Italy). J. Clean. Prod. 2020, 257, 120538. [CrossRef]

2. Kandi, A.; Moghimi, M.; Tahani, M.; Derakhshan, S. Optimization of pump selection for running as turbine and performance analysis within the regulation schemes. Energy 2021, 217, 119402. [CrossRef]

3. Al-Shetwi, A.Q.; Hannan, M.A.; Jern, K.P.; Mansur, M.; Mahlia, T.M.I. Grid-connected renewable energy sources: Review of the recent integration requirements and control methods. J. Clean. Prod. 2020, 253, 119831. [CrossRef]

4. Namahoro, J.P.; Wu, Q.; Xiao, H.; Zhou, N. The asymmetric nexus of renewable energy consumption and economic growth: New evidence from Rwanda. Renew. Energy 2021, 174, 336-346. [CrossRef]

5. Namahoro, J.P.; Wu, Q.; Xiao, H.; Zhou, N. The Impact of Renewable Energy, Economic and Population Growth on $\mathrm{CO}_{2}$ Emissions in the East African Region: Evidence from Common Correlated Effect Means Group and Asymmetric Analysis. Energies 2021, 14, 312. [CrossRef]

6. Hamududu, B.; Killingtveit, A. Assessing Climate Change Impacts on Global Hydropower. Energies 2012, 5, 305-322. [CrossRef]

7. Hamududu, B.H.; Killingtveit, Å. Hydropower Production in Future Climate Scenarios: The Case for Kwanza River, Angola. Energies 2016, 9, 363. [CrossRef]

8. Haidar, A.M.A.; Senan, M.F.M.; Noman, A.; Radman, T. Utilization of pico hydro generation in domestic and commercial loads. Renew. Sustain. Energy Rev. 2012, 16, 518-524. [CrossRef]

9. Ismail, M.A.; Othman, A.K.; Islam, S.; Zen, H. End Suction Centrifugal Pump Operating in Turbine Mode for Microhydro Applications. Adv. Mech. Eng. 2014, 6, 139868. [CrossRef]

10. Motwani, K.H.; Jain, S.V.; Patel, R.N. Cost Analysis of Pump as Turbine for Pico Hydropower Plants-A Case Study. Procedia Eng. 2013, 51, 721-726. [CrossRef]

11. Ranjitkar, G.; Huang, J.; Tung, T. In Proceedings of the Application of Micro-Hydropower Technology for Remote Regions, EIC Climate Change Technology. Ottawa, ON, Canada, 10-12 May 2006; pp. 1-10.

12. Renzi, M.; Rudolf, P.; Štefan, D.; Nigro, A.; Rossi, M. Installation of an axial Pump-as-Turbine (PaT) in a wastewater sewer of an oil refinery: A case study. Appl. Energy 2019, 250, 665-676. [CrossRef]

13. Moazeni, F.; Khazaei, J. Optimal energy management of water-energy networks via optimal placement of pumps-as-turbines and demand response through water storage tanks. Appl. Energy 2021, 283, 116335. [CrossRef]

14. Du, J.; Shen, Z.; Yang, H. Study on the effects of runner geometries on the performance of inline cross-flow turbine used in water pipelines. Sustain. Energy Technol. Assess. 2020, 40, 100762. [CrossRef]

15. Du, J.; Shen, Z.; Yang, H. Effects of different block designs on the performance of inline cross-flow turbines in urban water mains. Appl. Energy 2018, 228, 97-107. [CrossRef]

16. Jiyun, D.; Zhicheng, S.; Hongxing, Y. Numerical study on the impact of runner inlet arc angle on the performance of inline cross-flow turbine used in urban water mains. Energy 2018, 158, 228-237. [CrossRef] 
17. Jiyun, D.; Zhicheng, S.; Hongxing, Y. Study on the effects of blades outer angle on the performance of inline cross-flow turbines. Energy Procedia 2019, 158, 1039-1045. [CrossRef]

18. Hosseini, S.M.H.; Forouzbakhsh, F.; Rahimpoor, M. Determination of the optimal installation capacity of small hydro-power plants through the use of technical, economic and reliability indices. Energy Policy 2005, 33, 1948-1956. [CrossRef]

19. Mishra, S.; Singal, S.K.; Khatod, D.K. Optimal installation of small hydropower plant-A review. Renew. Sustain. Energy Rev. 2011, 15, 3862-3869. [CrossRef]

20. Williams, A.A. Pumps as turbines for low cost micro hydro power. Renew. Energy 1996, 9, 1227-1234. [CrossRef]

21. Ramos, H.; Borga, A. Pumps as turbines: An unconventional solution to energy production. Urban Water 1999, 1, 261-263. [CrossRef]

22. Mercier, T.; Hardy, C.; Van Tichelen, P.; Olivier, M.; De Jaeger, E. Control of variable-speed pumps used as turbines for flexible grid-connected power generation. Electr. Power Syst. Res. 2019, 176, 105962. [CrossRef]

23. Kusakana, K. A survey of innovative technologies increasing the viability of micro-hydropower as a cost effective rural electrification option in South Africa. Renew. Sustain. Energy Rev. 2014, 37, 370-379. [CrossRef]

24. Jain, S.V.; Patel, R.N. Investigations on pump running in turbine mode: A review of the state-of-the-art. Renew. Sustain. Energy Rev. 2014, 30, 841-868. [CrossRef]

25. Patelis, M.; Kanakoudis, V.; Gonelas, K. Pressure Management and Energy Recovery Capabilities Using PATs. Procedia Eng. 2016, 162, 503-510. [CrossRef]

26. Adu, D.; Jianguo, D.; Darko, R.O.; Boamah, K.B.; Emmanuel, A. Investigating the state of renewable energy and concept of pump as turbine for energy generation development. Energy Rep. 2020, 6, 60-66. [CrossRef]

27. Asomani, S.N.; Yuan, J.; Wang, L.; Appiah, D.; Zhang, F. Geometrical effects on performance and inner flow characteristics of a pump-as-turbine: A review. Adv. Mech. Eng. 2014, 12. [CrossRef]

28. Kaunda, C.S.; Kimambo, C.Z.; Nielsen, T.K. A technical discussion on microhydropower technology and its turbines. Renew. Sustain. Energy Rev. 2014, 35, 445-459. [CrossRef]

29. Štefan, D.; Rossi, M.; Hudec, M.; Rudolf, P.; Nigro, A.; Renzi, M. Study of the internal flow field in a pump-as-turbine (PaT): Numerical investigation, overall performance prediction model and velocity vector analysis. Renew. Energy 2020, 156, 158-172. [CrossRef]

30. Lin, T.; Li, X.; Zhu, Z.; Xie, J.; Li, Y.; Yang, H. Application of enstrophy dissipation to analyze energy loss in a centrifugal pump as turbine. Renew. Energy 2021, 163, 41-55. [CrossRef]

31. Hongyu, G.; Wei, J.; Yuchuan, W.; Hui, T.; Ting, L.; Diyi, C. Numerical simulation and experimental investigation on the influence of the clocking effect on the hydraulic performance of the centrifugal pump as turbine. Renew. Energy 2021, 168, 21-30. [CrossRef]

32. Morabito, A.; Vagnoni, E.; Di Matteo, M.; Hendrick, P. Numerical investigation on the volute cutwater for pumps running in turbine mode. Renew. Energy 2021, 175, 807-824. [CrossRef]

33. Ghorani, M.M.; Sotoude Haghighi, M.H.; Maleki, A.; Riasi, A. A numerical study on mechanisms of energy dissipation in a pump as turbine (PAT) using entropy generation theory. Renew. Energy 2020, 162, 1036-1053. [CrossRef]

34. Ghorani, M.M.; Sotoude Haghighi, M.H.; Riasi, A. Entropy generation minimization of a pump running in reverse mode based on surrogate models and NSGA-II. Int. Commun. Heat Mass Transf. 2020, 118, 104898. [CrossRef]

35. Wang, T.; Wang, C.; Kong, F.; Gou, Q.; Yang, S. Theoretical, experimental, and numerical study of special impeller used in turbine mode of centrifugal pump as turbine. Energy 2017, 130, 473-485. [CrossRef]

36. Sengpanich, K.; Bohez, E.L.J.; Thongkruer, P.; Sakulphan, K. New mode to operate centrifugal pump as impulse turbine. Renew. Energy 2019, 140, 983-993. [CrossRef]

37. Patelis, M.; Kanakoudis, V.; Gonelas, K. Combining pressure management and energy recovery benefits in a water distribution system installing PATs. J. Water Supply Res. Technol. Aqua 2017, 66, 520-527. [CrossRef]

38. Cimorelli, L.; D'Aniello, A.; Cozzolino, L.; Pianese, D. Leakage reduction in WDNs through optimal setting of PATs with a derivative-free optimizer. J. Hydroinform. 2020, 22, 713-724. [CrossRef]

39. Postacchini, M.; Darvini, G.; Finizio, F.; Pelagalli, L.; Soldini, L.; Di Giuseppe, E. Hydropower Generation Through Pump as Turbine: Experimental Study and Potential Application to Small-Scale WDN. Water 2020, 12, 958. [CrossRef]

40. Pérez-Sánchez, M.; Sánchez-Romero, F.J.; Ramos, H.M.; López-Jiménez, P.A. Improved Planning of Energy Recovery in Water Systems Using a New Analytic Approach to PAT Performance Curves. Water 2020, 12, 468. [CrossRef]

41. Stefanizzi, M.; Capurso, T.; Balacco, G.; Binetti, M.; Camporeale, S.M.; Torresi, M. Selection, control and techno-economic feasibility of Pumps as Turbines in Water Distribution Networks. Renew. Energy 2020, 162, 1292-1306. [CrossRef]

42. Kougias, I.; Aggidis, G.; Avellan, F.; Deniz, S.; Lundin, U.; Moro, A.; Muntean, S.; Novara, D.; Pérez-Díaz, J.I.; Quaranta, E.; et al. Analysis of emerging technologies in the hydropower sector. Renew. Sustain. Energy Rev. 2019, 113, 109257. [CrossRef]

43. Lima, G.M.; Luvizotto, E.; Brentan, B.M. Selection and location of Pumps as Turbines substituting pressure reducing valves. Renew. Energy 2017, 109, 392-405. [CrossRef]

44. Polák, M. The Influence of Changing Hydropower Potential on Performance Parameters of Pumps in Turbine Mode. Energies 2019, 12, 2103. [CrossRef]

45. Spedaletti, S.; Rossi, M.; Comodi, G.; Salvi, D.; Renzi, M. Energy recovery in gravity adduction pipelines of a water supply system (WSS) for urban areas using Pumps-as-Turbines (PaTs). Sustain. Energy Technol. Assess. 2021, 45, 101040. 
46. Carravetta, A.; Del Giudice, G.; Fecarotta, O.; Ramos, H.M. Pump as Turbine (PAT) Design in Water Distribution Network by System Effectiveness. Water 2013, 5, 1211-1225. [CrossRef]

47. Carravetta, A.; Del Giudice, G.; Fecarotta, O.; Ramos, H.M. Energy Production in Water Distribution Networks: A PAT Design Strategy. Water Resour. Manag. 2012, 26, 3947-3959. [CrossRef]

48. Carravetta, A.; del Giudice, G.; Fecarotta, O.; Ramos, H. PAT Design Strategy for Energy Recovery in Water Distribution Networks by Electrical Regulation. Energies 2013, 6, 411-424. [CrossRef]

49. Fecarotta, O.; Carravetta, A.; Ramos, H.M.; Martino, R. An improved affinity model to enhance variable operating strategy for pumps used as turbines. J. Hydraul. Res. 2016, 54, 332-341. [CrossRef]

50. Delgado, J.; Ferreira, J.P.; Covas, D.I.C.; Avellan, F. Variable speed operation of centrifugal pumps running as turbines. Experimental investigation. Renew. Energy 2019, 142, 437-450. [CrossRef]

51. Lima Gustavo, M.; Luvizotto, E.; Brentan Bruno, M.; Ramos Helena, M. Leakage Control and Energy Recovery Using Variable Speed Pumps as Turbines. J. Water Resour. Plan. Manag. 2018, 144, 04017077. [CrossRef]

52. Tahani, M.; Kandi, A.; Moghimi, M.; Houreh, S.D. Rotational speed variation assessment of centrifugal pump-as-turbine as an energy utilization device under water distribution network condition. Energy 2020, 213, 118502. [CrossRef]

53. Jain, S.V.; Swarnkar, A.; Motwani, K.H.; Patel, R.N. Effects of impeller diameter and rotational speed on performance of pump running in turbine mode. Energy Convers. Manag. 2015, 89, 808-824. [CrossRef]

54. Fernández, J.; Blanco, E.; Parrondo, J.; Stickland, M.T.; Scanlon, T.J. Performance of a centrifugal pump running in inverse mode. Proc. Inst. Mech. Eng. Part A J. Power Energy 2004, 218, 265-271. [CrossRef]

55. Han, Y.; Tan, L. Influence of rotating speed on tip leakage vortex in a mixed flow pump as turbine at pump mode. Renew. Energy 2020, 162, 144-150. [CrossRef]

56. Menter, F.R. Two-Equation Eddy-Viscosity Turbulence Models for Engineering Applications. AIAA J. 1994, $32,1598-1605$. [CrossRef]

57. Wilcox, D.C. Reassessment of the scale-determining equation for advanced turbulence models. AIAA J. 1988, 26, 1299-1310. [CrossRef]

58. Jones, W.P.; Launder, B.E. The prediction of laminarization with a two-equation model of turbulence. Int. J. Heat Mass Transf. 1972, 15, 301-314. [CrossRef]

59. Menter, F. Zonal Two Equation k-w Turbulence Models For Aerodynamic Flows. In Proceedings of the 23rd Fluid Dynamics, Plasmadynamics, and Lasers Conference, American Institute of Aeronautics and Astronautics, Orlando, FL, USA, 6-9 July 1993. 